Cómo citar este trabajo: Silva Pérez, R., \& Fernández Salinas, V. (2020). Unesco's territorial regarding (and disregarding) on its territorial heritage programmes: World Heritage Convention, Man and the Biosphere Programme (MaB) and International Geoscience and Geoparks Programme. Boletín de la Asociación de Geógrafos Españoles, (86). https://doi.org/10.21138/bage.2987

\title{
La consideración (y desconsideración) del territorio en los programas patrimoniales territoriales de la Unesco: Convención del Patrimonio Mundial, Programa Hombre y Biosfera (MaB) y Programa Internacional de Ciencias de la Tierra y Geoparques
}

Unesco's territorial regarding (and disregarding) on its territorial heritage programmes: World Heritage Convention, Man and the Biosphere Programme (MaB) and International Geoscience and Geoparks Programme

\author{
Rocío Silva Pérez \\ rsilva@us.es \\ Víctor Fernández Salinas \\ salinas@us.es \\ Departamento de Geografía Humana \\ Universidad de Sevilla (España)
}

\section{Resumen}

Desde su creación en 1945 la Unesco ha experimentado un progresivo acercamiento al territorio. Ello ha tenido lugar principalmente, aunque no solo, a través de los programas encaminados a la preservación del patrimonio natural y cultural, un campo en el que la organización se ha convertido en referente doctrinario y en marchamo de prestigio. Pero el territorio no siempre aparece en ellos de forma explícita y como referente claro. Las informaciones territoriales son a menudo superficiales y de carácter disperso, fragmentario y casi críptico. Este artículo pretende identificar las formas en las que el territorio está presente en los 
programas patrimoniales territoriales de la Unesco. A tal fin, se procede a la conceptuación e identificación de esos programas y se indaga en sus referentes espaciales desde una doble acepción de territorio (una de carácter político-administrativo y otra de carácter geográfico) y a partir de dos escalas espaciales aparentemente opuestas (la global y la local). Se concluye en la prelación de la Unesco por el territorio político frente al territorio geográfico, particularmente en las escalas globales; en cambio, en las locales, el territorio visto en clave geográfica cobra relevancia, aunque siempre con un importante protagonismo de los Estados.

Palabras clave: Unesco; patrimonio; Lista del Patrimonio Mundial; Reservas de la Biosfera; Red Mundial Geoparques.

\begin{abstract}
Since its creation in 1945 Unesco has experienced a progressive approach to the territory. This has taken place mainly, but not only, through programmes aimed at the preservation of natural and cultural heritage, a field in which the organization has become a doctrinal reference and in label of prestige. But the territory does not always appear explicitly in them and as a clear reference. Territorial information is often superficial and with dispersed, fragmentary and almost cryptic nature. This paper aims to identify the ways in which the territory is present in Unesco's territorial heritage programmes. In order to do so, these programmes are conceptualized, identifyed and researched in their spatial references from a dual kind concept of territory (political-administrative and geographical) and from two seemingly opposing spatial scales (global and local). It is concluded, with the preference of Unesco by the political territory against the geographical one, particularly at global scales; instead, in local ones, the territory seen in geographical bases becomes more and more relevant, although always with an important prominence of the States.
\end{abstract}

Key words: Unesco; heritage; World Heritage List; Biosphere Reserves; Global Geoparks Network.

\title{
1 Introducción
}

\subsection{Planteamientos de partida, objetivos y fuentes}

La Unesco se creó tras la Segunda Guerra Mundial con el fin de tender lazos que fomentasen un espíritu pacifista entre sus Estados miembros. El soporte para ello son los tres pilares básicos que conforman su acrónimo: la educación, la ciencia y la cultura. De ellos emanan principios generales de traslación universal y sin anclaje espacial definido por cuanto que su aplicación no 
entiende de fronteras: la educación obligatoria, universal y gratuita en sus tramos básicos; el conocimiento científico como palanca de progreso socioeconómico; o el respeto y la preservación de la diversidad cultural y ambiental del planeta. Estos planteamientos, de escasa o nula referencia espacial, no han sido incompatibles, sin embargo, con un progresivo acercamiento al territorio por parte de la Unesco. Este ha ganado presencia en el espíritu y estructura de la organización, particularmente, aunque no solo, a través de los programas encaminados a la preservación del patrimonio natural y cultural; un marco en el que esta institución se ha convertido en crisol doctrinario y en marchamo de prestigio internacional (Fernández Cacho, 2019; Isar, 2011). Pero los planteamientos territoriales de la Unesco no siempre son explícitos y la mayor parte de las veces se manifiestan de forma indirecta, fragmentada e incluso críptica; tampoco son sistemáticos y cada programa tiene su propia forma de entender el territorio. No es de extrañar, en este contexto, que la disquisición sobre las implicaciones y derivaciones territoriales de estos programas patrimoniales sea un aspecto poco tratado en contraste con el acercamiento del patrimonio al territorio y el protagonismo de facto que la Unesco ha tenido en ello. El tratamiento disgregado del patrimonio natural y cultural por las instituciones y la literatura especializada también está en la base de ese desencuentro. Este artículo pretende superar estos supuestos. Su objeto es explicitar las formas en las que el territorio está presente en el marco de la Unesco a través de sus programas patrimoniales de calado territorial, independientemente de que se dirijan al patrimonio natural o al cultural (división, por otro lado, con cada vez menos sentido). Subsidiariamente también se persigue:

a) Abundar en el marco epistemológico en que se sustenta el acercamiento del patrimonio al territorio.

b) Conceptuar y caracterizar de forma comparada las principales iniciativas patrimoniales de dimensión territorial de la Unesco (los denominados en este artículo programas patrimoniales territoriales) y sus registros en listas y redes.

c) Analizar la consideración (desconsideración) del territorio por la Unesco a través de dichos programas, insistiendo en sus diferencias en la forma de entenderlo y darle significado. Esto se establece desde el reconocimiento de la complejidad del concepto territorio en lo que tiene que ver tanto con sus significados multidimensionales (en particular con dos de sus acepciones básicas: la del territorio político-administrativo y la del territorio en clave geográfica), como con las distintas escalas espaciales desde la que es susceptible su estudio (la escala global, o planetaria, y la local, o propia de los lugares inscritos en listados y redes). 
Respecto a las fuentes, además de las referencias bibliográficas citadas ofrecidas al final del artículo, se han consultado la información y registros relacionados con la Unesco disponibles en sus páginas web dedicadas a la Convención; ${ }^{1}$ al Programa MaB ${ }^{2}$ y al Programa de Ciencias de la Tierra y Geoparques. ${ }^{3}$ El acceso a esta información y la identificación y comparación de los bienes incluidos en tales registros no ha resultado una tarea fácil. La Unesco no siempre es sistemática en cuanto a los datos territoriales que aporta. Así, a título de ejemplo, el número de bienes de algunos registros se contabiliza, unas veces, con relación a las declaraciones unitarias y, otras, en razón del número de Estados en los que se encuentran (lo que genera cifras más elevadas al estar bastantes de ellos en dos o más países). Esta falta de sistematización, que cabe interpretarse ya como indicio de una desconsideración del territorio, ha obligado a analizar pormenorizadamente y cotejar cada uno de los registros a fin de obtener información homologable y comparable. Esta labor constituye una de las aportaciones de este artículo.

\subsection{La incorporación del territorio al acervo patrimonial: el marco epistemológico}

El acercamiento entre territorio y patrimonio ha originado una abundante literatura sobre los mecanismos que han operado ese proceso. En ella se subraya la aproximación (conceptual y normativa) del patrimonio natural y cultural, tradicionalmente tratados por separado y considerados hoy como bienes indisolubles en los territorios (Francioni \& Lenzerini, 2008; King, 2016; Ortega Valcárcel, 1998). El gran protagonismo actual de tipologías patrimoniales que emergieron a lo largo del siglo XX muy vinculadas en sus valores al espacio que ocupan o en el que se desenvuelven (como el patrimonio inmaterial -Bortolotto, 2014; Rodrigo Cámara \& Díaz Iglesias, 2011-; el patrimonio industrial y de la obra pública -Benito del Pozo, 2002; Pardo Abad, 2010-; los paisajes y los itinerarios culturales _Fernández Salinas, 2013; Gómez Mendoza, 2013; Mata Olmo, 2010-) constituye otro indicador de la incorporación del territorio al acervo patrimonial. En paralelo, las finalidades de las declaraciones patrimoniales se han reenfocado desde una visión estática centrada en la preservación a otra orientada al uso de los bienes patrimoniales con fines divulgativos, pedagógicos y económicos. De hecho, la lógica utilitaria y economicista del patrimonio logra imponerse desde el reconocimiento, reivindicado pero no demostrado, de su capacidad para impulsar un desarrollo territorial equilibrado y

1 Unesco (n.d.). Unesco website. Retrieved from https://whc.unesco.org

2 Unesco (n.d.). Programa MaB. Retrieved from http://www.unesco.org/new/es/naturalsciences/environment/ecological-sciences/man-and-biosphere-programme/

3 Unesco (n.d.). List of UNESCO Global Geoparks (UGGp). Retrieved from http://www.unesco.org/new/en/natural-sciences/environment/earth-sciences/unesco-global-geoparks/list-ofunesco-global-geoparks/ 
armónico (Graham, Ashworth \& Tunbridge, 2016; Alonso Hierro \& Martín Fernández, 2013). Han proliferado los estudios sobre la incorporación de recursos patrimoniales en programas de turismo cultural (Troitiño Vinuesa, 2012; Zárate Martín, 2017); en planes de desarrollo sostenible de espacios naturales protegidos (Romero Calcerrada, 2002; Sánchez Cortez, 2013); en rutas turísticas, gastronómicas o enológicas (Hernández Ramírez, 2011; López-Guzmán \& Jesus, 2011; Ruiz Romero de la Cruz, Cruz Ruiz \& Zamarreño Aramendia, 2017); o como recurso estratégico en mercados agroindustriales muy competitivos y donde la cultura cotiza al alza, como es el caso de candidaturas recientes de paisajes vitivinícolas de la Lista del Patrimonio Mundial (en adelante Lista; Climent-López \& Esteban-Rodríguez, 2018; Martínez Arnaiz, Baraja Rodríguez \& Molinero Hernando, 2019; Silva Pérez \& Fernández Salinas, 2018).

Bajo estas transformaciones, subyace un nuevo paradigma patrimonial en el que el foco de atención se desplaza desde el objeto (el bien patrimonial) al sujeto (individuo o colectivo que le confiere valor y significado -Criado-Boado \& Barreiro, 2013; Silva Pérez \& Fernández Salinas, 2017-). Esto recibe un fuerte impulso con los principios de la convención marco del Consejo de Europa sobre los Valores del patrimonio cultural para la sociedad, o Convención de Faro (Consejo de Europa, 2005), que, si bien fue concebida para los Estados miembros de ese consejo, ha tenido una amplia proyección transcontinental. El patrimonio se entiende en esa lógica como un devenir y no como una realidad estática: "es un proceso creativo, dinámico y multidimensional, a través del cual una sociedad funde, protege, enriquece y proyecta su cultura" (Repetto, 2006: s.p.); así, además de patrimonio, se habla ahora de patrimonialización, entendida esta como las dinámicas conducentes a la toma de poder social e institucional sobre los bienes patrimoniales (Dormaels, 2012; Stephens \& Tiwari, 2015).

Los agentes cobran peso en los discursos, especialmente los institucionales por su capacidad normativa y, entre ellos, el de mayor rango y proyección internacional: la Unesco. Una creciente espacialidad lo impregna todo (a los bienes patrimoniales; a los programas y agentes de patrimonialización; a los fines del patrimonio, etc.). Así, el territorio cobra peso en las bases epistemológicas patrimoniales; primero como contenedor de bienes, que es la lógica subyacente al concepto normativo de entorno (Castillo Ruiz, 1997) y de zonas de amortiguamiento o buffer zones de algunos programas de la Unesco (véase más adelante). Más tarde es asumido como bien patrimonial con categoría sustantiva desde una doble vía: a) a través de nuevas figuras con notable calado territorial (paisajes culturales, itinerarios culturales, paisajes urbanos históricos, etc.); y b) a partir de la consideración del valor patrimonial de espacios naturales protegidos (Martínez Yáñez, 2008; Múgica de la Guerra et al., 2020). 
La apreciación del patrimonio como un recurso territorial remite, a su vez, a la nueva acepción del territorio antes aludida: la de receptor de programas patrimoniales que, convenientemente activados, impulsan su desarrollo. La Unesco, como organismo de referencia internacional en materia de patrimonio, ha desempeñado un papel clave en la evolución desde la acepción de territorio-contenedor, pasando por la de territorio-patrimonio, hasta la de territorio-receptor de programas patrimoniales soporte del trinomio patrimonio-territorio-desarrollo hoy dominante en los discursos (Caravaca et al., 1996; Deegan, 2012; Lorusso, Cogo \& Natali, 2017); al tiempo que sus dictámenes han sido determinantes en la incorporación del espacio a las legislaciones sobre el patrimonio natural y cultural de los Estados (Forrest, 2010; Iglesias Skuli, 2011).

Entre la abundante literatura teórica sobre la incorporación del territorio al conocimiento patrimonial, en parte ya comentada, interesa resaltar aquí la desarrollada en el marco del programa de investigación en el que se inserta este artículo sobre las relaciones patrimonioterritorio-desarrollo continuado en sucesivos proyectos de planes nacionales (SEJ2006-15331C02-01; CSO2009-12225-C05-05, CSO2012-39564-C07-07; CSO2015-65787-C6-6-P), de planes excelencia de la Junta de Andalucía (P12-SEJ-2024; G-GI3000/IDIA) o de la Unión Europea (INV-2016-T/I-001); amén de numerosos estudios sobre qué son los paisajes patrimoniales y cómo analizarlos según las distintas dominantes de su carácter (natural, rural o urbana; Mata Olmo, 2017; Silva Pérez, Fernández Salinas \& Mata Olmo, 2018). En 2015 el foco de atención de ese programa derivó hacia los paisajes culturales de la Lista, en los criterios para identificarlos y en las claves para gestionarlos (proyecto CSO2015-65787-C6-6-P; Baraja Rodríguez, García de Celis y Herrera Luque, 2019; Fernández Salinas \& Silva Pérez, 2016; Gurrutxaga San Vicente \& Porcal Gonzalo, 2019; Vadrí Fortuny \& Tort Donada, 2017).

Este artículo arranca de esos estudios, pero abre una línea nueva sobre la consideración del territorio en el marco de los programas patrimoniales de la Unesco. La finalidad de esta línea es avanzar en una lectura geográfica aplicada y crítica de los referentes doctrinarios, operativos y programáticos de dicha organización respecto al territorio. Para ello se es consciente de que el interés de la Unesco respecto a este territorio es paralelo muy a menudo al desconocimiento de sus claves geográficas básicas. Como hipótesis de trabajo se parte de que, en el protagonismo creciente del territorio en el marco de los programas patrimoniales de la organización, este no siempre aparece de manera explícita o lo hace de forma desenfocada. Como segunda hipótesis se mantiene que el territorio, aunque motor de buena parte de la renovación conceptual y de la acción tutelar y gestora del patrimonio en el marco de la Unesco, asoma en sus programas de forma desequilibrada a causa de que la institución lo entiende con diferentes acepciones y 
significados en razón de la propia complejidad del concepto de territorio y de la escala espacial a la que este se considere.

\subsection{La consideración (o desconsideración) del territorio por parte de la Unesco: propuesta metodológica}

En términos metodológicos, se ha operado como sigue:

1. Se acuña el concepto programas patrimoniales territoriales, entendidos como aquellas iniciativas y convenciones intergubernamentales auspiciadas por la organización y con una vinculación en sus planteamientos (tácita o expresa) a los valores patrimoniales de los territorios. A tal fin, estos programas han de cumplir dos requisitos: a) la elaboración de listas de bienes con referencia espacial específica: registros patrimoniales territorializados; y b) que esos registros deban expresarse necesariamente a través de técnicas cartográficas; es decir, no solo con alusión a coordenadas geográficas u otros sistemas de localización alfanumérica.

2. En razón de lo anterior, se identifican tres programas patrimoniales territoriales y sus correspondientes registros: la Convención para la Protección del Patrimonio Mundial Cultural y Natural (en adelante Convención; Unesco, 1972) y la Lista que de ella deriva; el Programa sobre Hombre y Biosfera (en adelante MaB, 1971) y la Red de Reservas de la Biosfera a él vinculada; y el Programa Internacional de Ciencias de la Tierra y Geoparques (2015) y su Red Mundial de Geoparques. Otros programas inicialmente considerados, como la Convención Relativa a los Humedales de Importancia Internacional Especialmente como Hábitat de Aves Acuáticas, Ramsar (1971) o la Convención para la Salvaguardia del Patrimonio Cultural Inmaterial de la Humanidad (Unesco, 2003; Silva Pérez \& Fernández Salinas, 2019) fueron desestimados. El primero de ellos porque presenta un desarrollo y gestión independientes de la Unesco, ya que esta actúa solo como depositaria de su convenio. El segundo de los programas porque, pese a que la intangibilidad de los bienes de esta convención se vincula habitualmente a una espacialidad concreta (la dieta mediterránea se circunscribe a algunos Estados culturalmente ligados al Mediterráneo o el Carnaval de Barranquilla se celebra de forma invariable en esa ciudad colombiana), sus registros (en ninguno de los tres listados que la desarrollan) ni requieren delimitaciones específicas, ni se les exige una representación cartográfica precisa.

3. Tras la identificación de los programas patrimoniales territoriales y sus registros patrimoniales territorializados se procede al análisis de unos y otros desde la perspectiva de su 
consideración (o desconsideración) del territorio. A tal fin, este es entendido con una doble acepción: por una parte, como espacio político-administrativo expresado en unidades de gobierno con delimitaciones precisas y bien encajadas unas en otras (Estados y dentro de ellos, regiones, administraciones locales, etc.) y, por otra, como espacio, tal y como se entiende en clave geográfica, de límites más difusos y que resulta de la simbiosis entre un soporte natural, unos procesos de construcción histórica y unas dinámicas de apropiaciones institucionales y sociales traducidas en leyes, normas y procesos identitarios (Tabla 1). Amén de esa doble acepción de territorio, se manejan dos aproximaciones escalares: la escala global o planetaria consustancial a una organización internacional como la Unesco, con dos claves operativas para la organización: una política (expresada en una división del planeta propia que agrupa los Estados en cinco grandes regiones) y otra más cercana al territorio en registro geográfico, aunque solo parcialmente (y cuya proyección a la escala planetaria son los reinos biogeográficos). Por otra parte está la escala local, que es la intrínseca de los lugares incluidos en los registros; se trata por lo general de escalas medias-grandes (comarcas), grandes (centros históricos) o muy grandes, tanto que son escalas más propias de la arquitectura que de la geografía (edificios). Entre los tres programas patrimoniales territoriales se acercan a los 3000 sitios. Es precisamente en estas escalas locales en las que se aprecia toda la complejidad integradora entre: el marco natural (con un peso importante de las unidades estructurales y topográficas); los procesos de conformación y transformación histórica (concretados en puntos que representan unidades de poblamiento; en líneas que reproducen las vías de comunicación; y en áreas que proyectan usos del suelo); y sistemas de apropiaciones y regulaciones normativas (planes de ordenación del territorio; planes de uso y gestión de espacios naturales protegidos; planes de protección de conjuntos históricos, etc.). 
Tabla 1. Acepciones de territorio con relación a los programas patrimoniales de la Unesco

\begin{tabular}{|c|c|c|c|}
\hline \multirow{2}{*}{$\begin{array}{l}\text { ACEPCIÓN DE } \\
\text { TERRITORIO }\end{array}$} & \multirow{2}{*}{$\begin{array}{c}\text { CONCRECIONES Y } \\
\text { DETERMINACIONES PARA } \\
\text { LA UNESCO }\end{array}$} & \multicolumn{2}{|c|}{ PRINCIPALES SIGNIFICANTES } \\
\hline & & ESCALA GLOBAL & ESCALA LOCAL \\
\hline $\begin{array}{l}\text { Político- } \\
\text { administrativo }\end{array}$ & $\begin{array}{l}\text { - Es la consustancial de la } \\
\text { organización } \\
\text { - Los Estados son los } \\
\text { interlocutores inmediatos y } \\
\text { protagonistas }\end{array}$ & $\begin{array}{l}\text { Resulta de aglutinar los } \\
\text { Estados en regiones a } \\
\text { través de una división } \\
\text { planetaria particular de la } \\
\text { Unesco. }\end{array}$ & $\begin{array}{l}\text { Instituciones con poder } \\
\text { político, como regiones, } \\
\text { ayuntamientos, etc. }\end{array}$ \\
\hline \multirow{3}{*}{ En clave geográfica } & $\begin{array}{l}\text { Naturaleza (o infraestructura } \\
\text { territorial) }\end{array}$ & $\begin{array}{l}\text { Reinos y provincias } \\
\text { biogeográficas }\end{array}$ & $\begin{array}{l}\text { - Unidades } \\
\text { estructurales y } \\
\text { topográficas } \\
\text { - Climas locales } \\
\text { - Redes hidrográficas } \\
\text { - Unidades } \\
\text { biogeográficas } \\
\end{array}$ \\
\hline & $\begin{array}{l}\text { Procesos de construcción } \\
\text { histórica (o estructura territorial) }\end{array}$ & & $\begin{array}{l}\text { - Puntos: ciudades y } \\
\text { unidades de } \\
\text { asentamientos } \\
\text { - Ejes: vías de } \\
\text { comunicación } \\
\text { - Áreas: usos del suelo }\end{array}$ \\
\hline & $\begin{array}{l}\text { Sistemas identitarios y } \\
\text { normativos (o superestructura) }\end{array}$ & & $\begin{array}{l}\text { - Planes urbanísticos } \\
\text { y de ordenación del } \\
\text { territorio } \\
\text { - Planes de } \\
\text { ordenación y gestión } \\
\text { de recursos naturales } \\
\text { - Planes especiales de } \\
\text { protección de } \\
\text { conjuntos históricos }\end{array}$ \\
\hline
\end{tabular}

Fuente: elaboración propia

\section{Los programas patrimoniales territoriales de la Unesco y su consideración (desconsideración) del territorio en las escalas global y local}

2.1 La incorporación del territorio al acervo patrimonial de la Unesco. Los programas patrimoniales territoriales

Estos programas son la expresión más evidente de la incorporación del territorio a la doctrina patrimonial de la Unesco (Tabla 2) y se definen por el tipo de patrimonio por el que se interesan, por sus finalidades y por sus patrones de patrimonialización y de proyección espacial (ver más adelante la organización espacial; Tablas 3 y 4). 
La Convención y el Programa MaB tienen una dilatada trayectoria que se remonta a los años setenta del siglo XX. Sus planteamientos, aunque avanzados para aquel momento, responden a una concepción ya superada del patrimonio, particularmente si se comparan con el Programa Internacional de Ciencias de la Tierra y Geoparques, mucho más reciente y con postulados más acordes a los fundamentos patrimoniales actuales.

Los tres programas generan listados de bienes con clara expresión territorial. De la Convención deriva la Lista: un total de 1.121 bienes de distinta naturaleza (monumentos, conjuntos históricos, paisajes culturales, parques naturales, etc.) y de extensiones muy contrastadas. El área protegida de las islas Fénix (un conjunto de atolones de 40825000 ha en el océano Pacífico perteneciente a Estados Unidos y Kiritabi) es de los mayores, en tanto que la Casa Rietveld Schröder (en Utrecht -Países Bajos-, que ni siquiera alcanza un área -0,75-) es de los menores. El Programa MaB se proyecta en la Red de Reservas de la Biosfera: 680 espacios relativamente extensos (una media de 929373 ha), también con grandes contrastes: 97200000 ha en la reserva del noroeste de Groenlandia y 413 ha en el karst de Eslovenia como casos extremos. El Programa Internacional de Ciencias de la Tierra y Geoparques se concreta en la Red Mundial de Geoparques: 147 ámbitos con una extensión media más reducida (1775 ha). El mayor de ellos, el geoparque mundial de las Azores (Portugal), se aproxima a las 13000 ha y, en el extremo opuesto, el geoparque mundial de la costa de Copper (Irlanda), ronda las 50.

Respecto al tipo de patrimonio reconocido, la Convención se ha implementado más en el patrimonio cultural que en el natural y ha presentado siempre un sesgo monumental y urbano (aunque en los últimos años más matizado) en detrimento de los bienes naturales y mixtos. Las Directrices Prácticas para la Aplicación de la Convención del Patrimonio Mundial (en adelante Directrices Prácticas), que habían sido creadas para gestionar las actualizaciones y adendas a la Convención, intentaron corregir sin éxito el desequilibrio. Esto se hizo a partir de estrategias, orientaciones y obligaciones concretas, pero los bienes declarados por criterios culturales continúan prevaleciendo: 869 bienes culturales, 213 naturales y 39 mixtos (datos de 2019). El foco de atención del Programa MaB y del Programa Internacional de Ciencias de la Tierra y Geoparques es el patrimonio natural; más concretamente la riqueza biogeográfica, para el primero, y el patrimonio geológico, para el segundo. 
Tabla 2. Los programas patrimoniales territoriales de la Unesco

\begin{tabular}{|c|c|c|c|c|}
\hline & & $\begin{array}{l}\text { CONVENCIÓN DEL } \\
\text { PATRIMONIO MUNDIAL }\end{array}$ & PROGRAMA MAB & $\begin{array}{c}\text { PROGRAMA } \\
\text { INTERNACIONAL DE } \\
\text { CIENCIAS DE LA TIERRA } \\
\text { Y GEOPARQUES }\end{array}$ \\
\hline 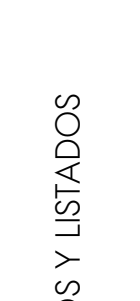 & $\begin{array}{l}\text { Textos de } \\
\text { referencia }\end{array}$ & $\begin{array}{l}\text { - Convención (Unesco, } \\
\text { 1972a) } \\
\text { - Directrices Prácticas } \\
\text { para la Aplicación de } \\
\text { la Convención (varias } \\
\text { publicaciones entre } \\
1977 \text { y 2019) }\end{array}$ & $\begin{array}{l}\text { - Programa sobre el } \\
\text { Hombre y la Biosfera, } \\
\text { MaB (1971) } \\
\text { - Marco estatutario (Unesco, } \\
\text { 1972b) } \\
\text { - Estrategia de Sevilla } \\
\text { (1995) }\end{array}$ & $\begin{array}{l}\text { Estatutos del programa } \\
\text { (2015) }\end{array}$ \\
\hline 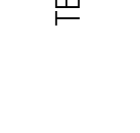 & $\begin{array}{l}\text { Listados y } \\
\text { redes }\end{array}$ & $\begin{array}{l}\text { Lista del Patrimonio } \\
\text { Mundial: } 1.121 \text { bienes } \\
\text { (2019) }\end{array}$ & $\begin{array}{l}\text { Red de Reservas de la } \\
\text { Biosfera: } 680 \text { reservas } \\
\text { (2019) }\end{array}$ & $\begin{array}{l}\text { Red Mundial de } \\
\text { Geoparques: } 147 \\
\text { geoparques (2019) }\end{array}$ \\
\hline $\begin{array}{l}\text { TIPO DE } \\
\text { PREDON }\end{array}$ & $\begin{array}{l}\text { PATRIMONIO } \\
\text { INANTE }\end{array}$ & $\begin{array}{l}\text { Cultural (monumentos, } \\
\text { conjuntos históricos, etc.) } \\
\text { y, a distancia, natural } \\
\text { (parques, reservas, etc.) }\end{array}$ & $\begin{array}{l}\text { Natural (riqueza } \\
\text { biogeográfica) }\end{array}$ & Natural (riqueza geológica) \\
\hline FINALID, & DES & $\begin{array}{l}\text { - Identificación } \\
\text { - Tutela } \\
\text { - Difusión } \\
\text { - Activación }\end{array}$ & $\begin{array}{l}\text { - Desarrollo sostenible } \\
\text { - Investigación } \\
\text { - Preservación de la } \\
\text { biodiversidad }\end{array}$ & $\begin{array}{l}\text { - Reconocimiento y } \\
\text { conservación del } \\
\text { patrimonio geológico } \\
\text { - Educación y turismo } \\
\text { - Desarrollo sostenible } \\
\text { - Concienciación } \\
\text { - Investigación }\end{array}$ \\
\hline 岁 $\frac{1}{\partial}$ & Procesos & De arriba abajo & Mixtos & De abajo arriba \\
\hline 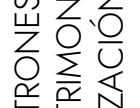 & Agentes & $\begin{array}{l}\text { - Estados } \\
\text { - Comunidades locales }\end{array}$ & $\begin{array}{l}\text { - Comunidades locales } \\
\text { - Estados }\end{array}$ & - Comunidades locales \\
\hline$a 0$ & Vigencia & Permanente & Revisable cada diez años & Revisable cada cuatro años \\
\hline 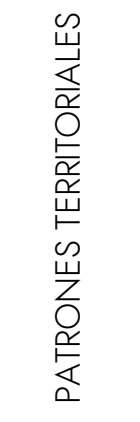 & $\begin{array}{l}\text { Proyección } \\
\text { espacial de } \\
\text { los bienes }\end{array}$ & $\begin{array}{l}\text { - Punto (monumentos) } \\
\text { - Línea (itinerarios, } \\
\text { canales) } \\
\text { - Áreas (paisajes } \\
\text { culturales, parques } \\
\text { naturales) } \\
\text { - Continuidades (bienes } \\
\text { transnacionales) } \\
\text { - Discontinuidades (bienes } \\
\text { en serie) }\end{array}$ & $\begin{array}{l}\text { - Áreas } \\
\text { - Continuidades (reservas } \\
\text { transnacionales) }\end{array}$ & $\begin{array}{l}\text { - Áreas } \\
\text { - Continuidades } \\
\text { (geoparques } \\
\text { transnacionales) }\end{array}$ \\
\hline
\end{tabular}

Fuente: elaboración propia 
Los citados sesgos cultural o natural de los programas, no obstante, nunca significaron exclusividad y los tres son desde sus inicios programas transversales en cuanto a la tipología de bienes concernidos y han evolucionado, además, hacia una mezcla de objetivos y una convergencia creciente entre sí. La Convención, pese al sesgo cultural antedicho, ejemplifica bien esa transversalidad recogida en su propio nombre y en buena parte de los criterios expresivos del valor universal excepcional (valor que acredita que el interés de un bien traspasa las fronteras del Estado en el que se halla). Los parágrafos 49 a 53 de las Directrices Prácticas (Capítulo II.A) se ocupan de la conceptuación de ese valor universal excepcional y los 79 a 95 (Capítulo II.D) de la definición de tales criterios (ver más adelante Tabla 5). Baste avanzar que el enunciado del criterio (viii) "Ofrecer ejemplos representativos de la historia de la tierra, incluyendo procesos geológicos creadores de formas geológicas significativas" resulta extrapolable a cualquier geoparque y que los bienes inscritos por ese criterio (caso del karst de la China meridional o los volcanes de Kamchatka en Rusia, entre otros) podrían formar parte de la Red Mundial de Geoparques. Otro tanto podría decirse respecto a los criterios (ix) "Ofrecer un ejemplo eminente de procesos ecológicos y biológicos en el curso de la evolución de los ecosistemas" y $(\mathrm{x})$ "Contener hábitat naturales representativos e importantes para la conservación de la biodiversidad" y a los bienes inscritos según ellos (como la reserva de fauna de Okapis, en la República Democrática del Congo, o las lagunas de Nueva Caledonia y sus arrecifes y ecosistemas conexos) que, además de formar parte de la Lista, podrían integrar la Red de Reservas de la Biosfera. Un ejemplo reciente de transversalidad programática en el marco de la Convención respecto a España es la candidatura del puente romano de Alcántara (Cáceres) como paisaje cultural, para lo que se valora su vinculación con la reserva de la biosfera del Tajo.

Otro ejemplo de confluencia programática tiene que ver con el acercamiento (más o menos explícito) de las finalidades de las declaraciones en lo concerniente a la utilización de los bienes como recurso para el desarrollo de los territorios. Los tres programas lo mencionan, aunque con matices diferenciados:

- La Convención señala las responsabilidades tradicionales respecto al patrimonio: identificación de bienes (inventario y catalogación), tutela, difusión y transmisión como legado. No elude su activación económica, aunque se refiere a ella en último lugar y prima la protección de los bienes. Pero esto último es solo sobre el papel y, a efectos prácticos, la intención económica se impone por parte de los Estados solicitantes de nuevas declaraciones. La presencia en la Lista se percibe como una marca de calidad turística (Bertacchini \& Saccone, 2012) y ello la ha convertido en uno de los listados patrimoniales más prestigiosos 
del planeta al que aspiran y por el compiten dichos Estados y, dentro de ellos, las ciudades y los territorios. No resulta casual la concentración de sus bienes en espacios económicamente pujantes y mejor equipados para encarar esa competencia (con Europa a la cabeza y especialmente sus zonas urbanas) frente a la menor presencia en los ámbitos de economía deprimida (países socioeconómicamente débiles y enclaves rurales). Ello redunda en una merma de sus potencialidades para la consecución de un desarrollo territorial armónico, que es uno de los fines explícitamente recogidos en la Convención y que, en la práctica, queda desvirtuado.

- El Programa MaB aúna objetivos de investigación, conservación y desarrollo, en principio sin ninguna prelación entre ellos, aunque resulta destacable el papel asignado al desarrollo sostenible de las comunidades que habitan las reservas, herencia de su vinculación original a los principios del ecodesarrollo (Estenssoro, 2015). La coincidencia territorial de las reservas de la biosfera con ámbitos económicamente deprimidos (países empobrecidos y áreas de montaña poco pobladas y vaciadas del mundo desarrollado), en los que el programa MaB está actuando como un catalizador de desarrollo (Brunel, 2008; Cid Carmona, 2009: Jaeger, 2005), es un ejemplo de la vocación de equilibrio territorial que persigue.

- El Programa de Ciencias de la Tierra y Geoparques es el más completo de los tres también en cuanto a intenciones. Su finalidad más novedosa es el reconocimiento y conservación del patrimonio geológico; pero, a la vez, pretende concienciar a las sociedades locales de la importancia de incluir ese patrimonio en programas de desarrollo que consideren todos los recursos patrimoniales presentes en cada geoparque (González-Tejada, Du, Read \& Girault, 2017; Henriques \& Brilha, 2017). Este es el único programa de los analizados que, de forma contundente y expresa, se refiere a la utilización de los bienes patrimoniales con fines turísticos. También es patente su intención de hacer concurrir en un mismo territorio todas las declaraciones patrimoniales de la Unesco existentes (o potenciales) en pro de su desarrollo.

Los procesos y agentes de patrimonialización difieren en cada programa. En la Convención los interlocutores ante la Unesco son los Estados, que se convierten por ello en agentes protagonistas. De ello deviene el predominio de la patrimonialización institucional (de arriba abajo) todavía prevalente pese a que las Directrices Prácticas han intentado corregirlo incentivando la participación de los actores locales en la elaboración de las candidaturas (parágrafos 64 y, sobre todo, 123). Su visión más tradicional del patrimonio encuentra su correlato en el entendimiento de este como una realidad estática y de valores inmanentes y esto se refleja en la vigencia permanente de sus registros: una vez que se consigue entrar en la Lista 
del Patrimonio Mundial raramente se sale de ella (solo dos bienes han sido eliminados de la Lista por impactos o amenazas en su valor universal excepcional: el refugio del órix -Omán- y el paisaje cultural del Elba a su paso por Dresde -Alemania--; y ello a pesar de la existencia de una Lista de Bienes en Peligro como hecho diferencial de este programa respecto a otros. El programa MaB muestra una situación intermedia en lo que a mecanismos de patrimonialización se refiere. Los proponentes de las reservas ante la Unesco también son los Estados, pero la configuración en red del programa les resta protagonismo y transfiere su gestión a las comunidades locales. De ello resulta una patrimonialización mixta entre estas comunidades y el Estado cuyo devenir es revisado cada diez años. En caso de pérdida de biodiversidad, las reservas abandonan la red, aunque pueden volver a ingresar si restauran los valores alterados. El Programa Internacional de Ciencias de la Tierra y Geoparques se rige por procesos de patrimonialización de abajo arriba y el protagonismo recae en los agentes sociales e institucionales que operan en los territorios.

Las espacialidades o referentes de la territorialidad de los bienes tiene distintas expresiones. Dos de las consideradas básicas para los propósitos de este trabajo son el tipo de proyección espacial particular de cada bien, por una parte, y la organización espacial de los listados, por otra. Con relación a la proyección espacial de los bienes, las diferencias entre programas, inicialmente importantes, se han ido matizando con su andadura. Un ejemplo de ello lo ofrece la Lista, que empezó prestando poca o ninguna atención al territorio en el que se insertaban sus bienes (lo que los convertía en autistas en su marco territorial) y que luego se ha hecho más sensible a las características de estos territorios a tenor de la evolución operada en el mundo del patrimonio. Destacan las áreas (especialmente los paisajes culturales y los parques naturales) y las líneas (itinerarios culturales, canales históricos, etc.). Los territorios de las reservas de la biosfera y de los geoparques tienen desde sus inicios una proyección espacial más potente, buena parte de ella de carácter comarcal o regional (con decenas, centenas o miles de hectáreas de extensión, según los casos), si bien en las reservas de la biosfera son también comunes las proyecciones lineales (corredores ecológicos).

\subsection{La consideración (y desconsideración) del territorio por la Unesco a escala global}

En tanto que organización internacional, el referente espacial directo de la Unesco es la escala global o planetaria. En la gestión de los programas patrimoniales a esta escala son varias las regionalizaciones que utiliza, aunque fundamentalmente se concretan en dos (Tabla 3): a) una división propia de la Unesco, mayoritariamente empleada en el marco de la Convención, que se estructura según criterios político-culturales y que organiza el mundo en cinco grandes regiones; 
y b) los reinos biogeográficos, preferentemente utilizada por los programas enfocados al patrimonio natural, particularmente por el Programa MaB, aunque la Convención también recurre a ella en el caso de los bienes inscritos en la Lista por criterios naturales (ver más adelante).

\section{Tabla 3. Equivalencia entre regiones y reinos biogeográficos}

\begin{tabular}{|c|c|}
\hline REGIONES PROPIAS DE LA UNESCO & REINOS BIOGEOGRÁFICOS \\
\hline \multirow{2}{*}{$\begin{array}{l}\text { Europa y Norteamérica ( } 65000000 \mathrm{~km}^{2} \text { ). Excluye } \\
\text { México e incorpora Siberia (incluye buena parte } \\
\text { del reino paleoártico y el neoártico) } \\
\text { Estados Árabes ( } 14000000 \mathrm{~km}^{2} \text { ). El islam actúa } \\
\text { como elemento aglutinador (forma parte del reino } \\
\text { paleoártico) }\end{array}$} & $\begin{array}{l}\text { Neoártico (22 } 900000 \text { km²). } \\
\text { Norteamérica (salvo parte de México y } \\
\text { sur de Florida) y Groenlandia }\end{array}$ \\
\hline & $\begin{array}{l}\text { Paleoártico (54 } 100000 \text { de } \mathrm{km}^{2} \text { ). } \\
\text { Eurasia (con la excepción del sudeste } \\
\text { asiático y del Indostán) y tercio norte de } \\
\text { África. }\end{array}$ \\
\hline $\begin{array}{l}\text { Latinoamérica y El Caribe }\left(20000000 \mathrm{~km}^{2}\right) \text {. Las } \\
\text { culturas ibéricas dan homogeneidad a la mayor } \\
\text { parte de esta región }\end{array}$ & $\begin{array}{l}\text { Neotropical }\left(19000000 \mathrm{~km}^{2}\right) \text {. } \\
\text { Centroamérica, Sudamérica y parte de } \\
\text { México. }\end{array}$ \\
\hline $\begin{array}{l}\text { África }\left(21000000 \mathrm{~km}^{2}\right) \text {. Está compuesto por } \\
\text { países subsaharianos con muy distintas tradiciones } \\
\text { culturales, en muchos casos segregadas por la } \\
\text { política de descolonización europea. }\end{array}$ & $\begin{array}{l}\left.\text { Afrotropical (22 } 100000 \mathrm{~km}^{2}\right) \text {. Centro y } \\
\text { sur de África }\end{array}$ \\
\hline \multirow{4}{*}{$\begin{array}{l}\text { Asia y El Pacífico (35 } 500000 \text { de } \mathrm{km}^{2} \text { ). Se trata } \\
\text { de un complejo espacio sobre dos continentes con } \\
\text { gran variedad de culturas asiáticas e importante } \\
\text { presencia de la occidental (sensiblemente mayor } \\
\text { que los tres reinos biogeográficos más o menos } \\
\text { equivalentes por incluir la totalidad de China, } \\
\text { Mongolia, Kazajistán y otros países próximos). }\end{array}$} & Australiano $\left(7700000 \mathrm{~km}^{2}\right)$. Australia \\
\hline & $\begin{array}{l}\left.\text { Indomalayo (7 } 500000 \mathrm{~km}^{2}\right) \text {. Sudeste } \\
\text { asiático e Indostán. }\end{array}$ \\
\hline & $\begin{array}{l}\text { Oceánico (1 } 000000 \text { km²). Oceanía } \\
\text { (salvo Australia y Nueva Zelanda) }\end{array}$ \\
\hline & Antártico (30000 000 km²). Antártida \\
\hline
\end{tabular}

Fuente: elaboración propia a partir de Udvardy (1975) y Lista del Patrimonio Mundial ${ }^{4}$

a) La regionalización planetaria propia de la Unesco

La estructuración planetaria en cinco regiones es una zonificación particular de la Unesco en el sentido de que ninguna otra organización gubernamental internacional o científica recurre a ella (Figura 1). La Unesco no explicita los criterios que la rigen ni las pautas de su organización y delimitación espacial. Podría decirse, en consecuencia, que se trata una regionalización basada 
en la agrupación de Estados por continentes y, sobre todo, por afinidades culturales (cultura occidental, oriental, latinoamericana, mundo árabe, etc.), lo que lleva a (a la vez que procede de) empoderamientos políticos colectivos (especialmente en África y Latinoamérica); es pues una regionalización eminentemente política.

Figura 1. Regiones planetarias de la Unesco

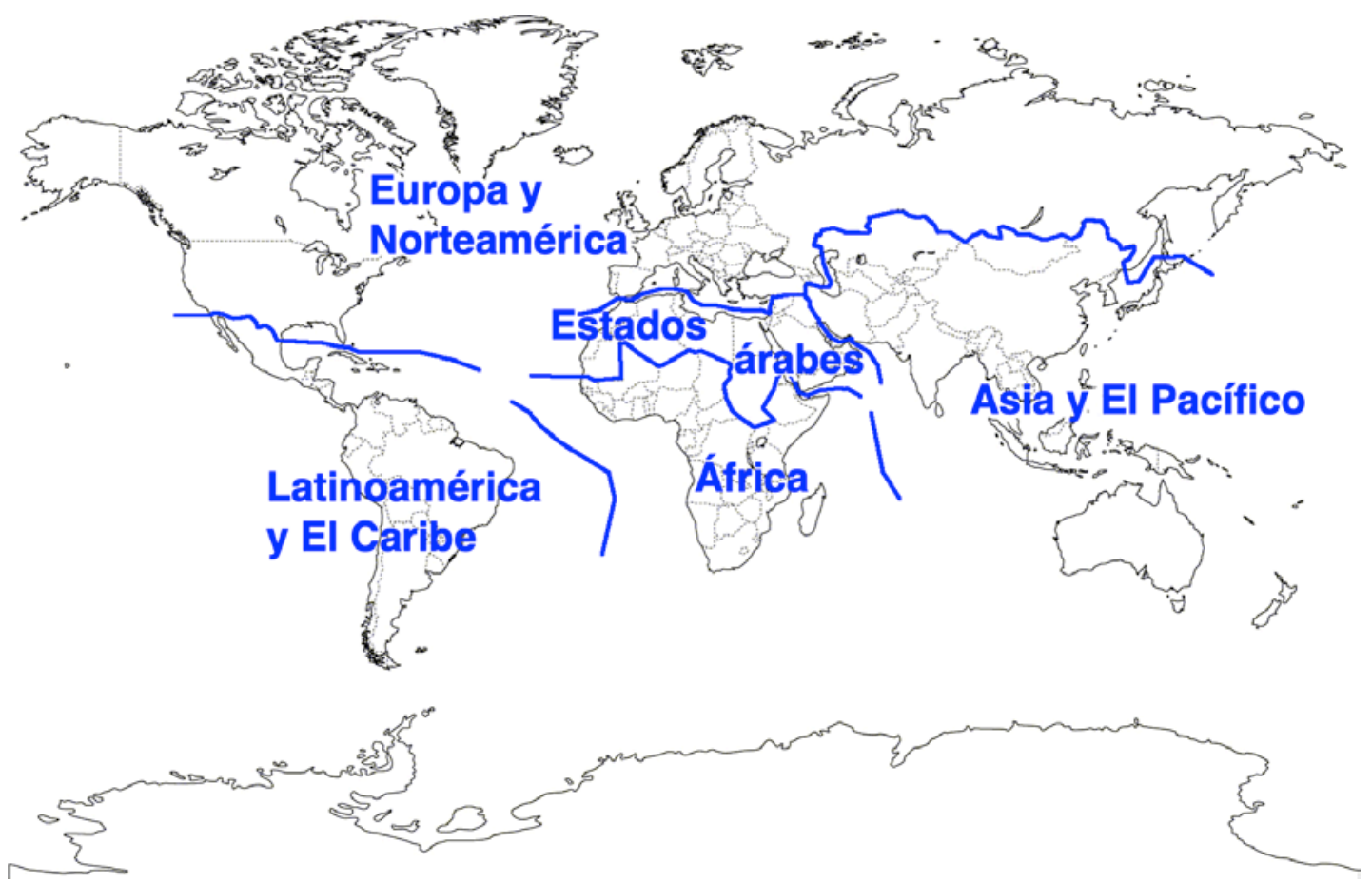

Fuente: elaboración propia a partir de del portal web de la Unesco ${ }^{5}$

El significado de las cinco grandes regiones aplicado a la Convención tiene que ver con una estrategia de distribución espacial equilibrada de sus bienes a escala planetaria siguiendo los patrones políticos citados. Desde la aprobación de la Estrategia Global para una Lista del Patrimonio Mundial Representativa, Equilibrada y Creíble (1994) y medidas posteriores, las posibilidades de prosperar de las candidaturas presentadas por los Estados está en buena parte condicionada (al menos sobre el papel, ya que las presiones políticas son determinantes) por la región planetaria a la que dichos Estados se adscriben y de la consideración (no siempre ajustada) que la Unesco hace de ellas al resolver que el valor universal excepcional que aportan las nuevas candidaturas ya está suficientemente representado, o no, en la Lista. A título de ejemplo, la posibilidad de incorporar nuevos bienes se hace más restrictiva en Europa y Norteamérica por ser la región planetaria mejor representada; pero no se tiene en cuenta que es la región objetivamente más extensa y que internamente alberga Estados con solo uno o dos 
bienes, como Azerbayán, Irlanda o Islandia. En el otro extremo, las regiones y subregiones con menos registros, como África, Pacífico o El Caribe (parágrafo 61 de las Directrices Prácticas para la Aplicación de la Convención del Patrimonio Mundial) tienen prioridad a la hora de aportar nuevos bienes. Ello manifiesta la importancia de las cinco regiones planetarias en la gestión de la Lista.

Esta no es la única regionalización utilizada por la Convención, que también hace uso de las regiones biogeográficas como argumento acreditativo del valor universal excepcional de los bienes inscritos por criterios naturales; pero lo hace en un plano muy secundario y con una intención meramente analítica frente al carácter estratégico de las cinco demarcaciones.

b) Los reinos biogeográficos

La segunda regionalización utilizada por la Unesco para la organización de los bienes a escala planetaria es la derivada de los reinos biogeográficos, preferentemente utilizada, como ya se ha dicho, por los programas encaminados a la preservación y gestión del patrimonio natural. Su ajuste a criterios científicos supone una diferencia básica respecto a la regionalización anterior; su sentido valorativo y analítico y su escaso significado estratégico también suponen una diferencia con respecto a aquella. De resultas de todo ello, el territorio entendido en clave geográfica es en ella, aunque de forma parcial, más reconocible.

La conceptuación de reino biogeográfico no está exenta de ambigüedades y el Programa MaB así lo recoge de forma expresa: "el término 'región biogeográfica principal' no está estrictamente definido [...pero tiene como referencia] al sistema de clasificación Udvardy" (Punto 4.1 del Formulario de Propuesta de Reserva de la Biosfera; Udvardy, 1975). Este sistema de clasificación había sido encargado por la Unión Internacional de Conservación de la Naturaleza como una contribución al Programa MaB.

Algunas de esas anfibologías tienen que ver precisamente con cierta confusión o mescolanza entre los términos reinos (de los que existen 8; Figura 2) y provincias biogeográficas (de las que se contabilizan 203). Esta distinción no es menor, tanto porque son taxones diferentes (Spalding et al., 2007; Olso et al., 2001) como, sobre todo, porque ambos se proyectan y son concebidos en diferentes escalas espaciales: los reinos son más fácilmente asimilables a la escala planetaria de la regionalización propia de la Unesco (volver a Tabla 3), en tanto que las provincias tienden a comprenderse mejor en la escala de los Estados. Tampoco hay que perder de vista, para entender el interés del Programa MaB en las provincias biogeográficas, que las propuestas de lugares aspirantes a integrar la Red de Reservas de la Biosfera (y esto podría 
aplicarse también a la Lista para algunos bienes naturales) proceden de los Estados y que esa es la escala, en términos de territorio político, en la que se dirimen los valores y las responsabilidades para su mantenimiento exigidos a las candidaturas.

Figura 2. Reinos biogeográficos de Udvardy

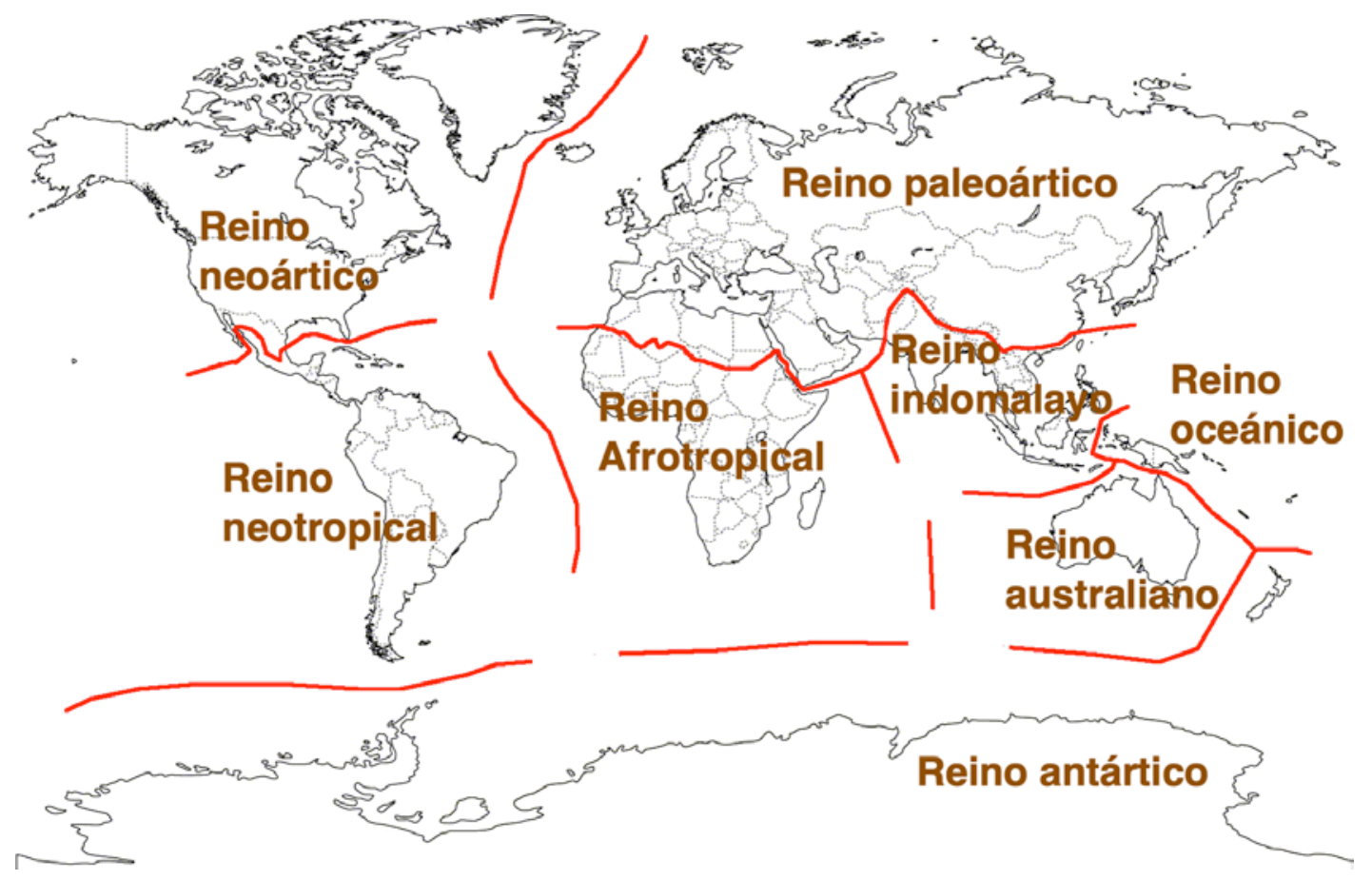

Fuente: elaboración propia a partir de Udvardy (1975)

Sin embargo, los equívocos taxonómicos antes mencionados no implican falta de rigor, ya que tanto los reinos como las provincias son identificados con criterios solventes y precisos. Atienden a similitudes biogeográficas a escala planetaria (los reinos) o a escalas intermedias (las provincias) de los siguientes parámetros: las afinidades de sus sistemas ecológicos (medidos por su diversidad de seres vivos y el número de endemismos) y las conexiones de dichos sistemas con el medio físico (dominios climáticos, sustratos geológicos, condiciones orográficas y litológicas, etc.). En consonancia con este planteamiento, en la regionalización de Udvardy, los reinos no tienen en cuenta en su delimitación (ni tampoco las provincias) las fronteras de los Estados y esta libertad de diseño les permite ajustarse más a criterios científicos (en este caso biogeográficos) que a otros de carácter político. No obstante, debe recordarse también respecto al Programa MaB (directamente relacionado con esta regionalización), o respecto a la Lista y la Red Mundial de Geoparques (que la utilizan, aunque secundariamente) que los Estados vuelven a ser protagonistas en tanto que también son los intermediarios necesarios entre las áreas propuestas y la Unesco. 


\subsection{La consideración (y desconsideración) del territorio por la Unesco a escala local}

La significación de la escala planetaria como referente espacial connatural de los programas patrimoniales territoriales de la Unesco no solapa la importancia de las escalas locales o propias de los bienes de los registros. Al contrario, pese a su marchamo científico global, los espacios que la Unesco entiende son los concretos. Los lugares de los registros patrimoniales territorializados son ámbitos espaciales individualmente identificados, delimitados y con nombres propios (reserva de la biosfera de Menorca -España- o geoparque mundial de la de Hexigten -China-). Sus configuraciones espaciales, dominantes y escalas territoriales son muy dispares: puntuales o de gran escala (monumentos y centros históricos, que son los más abundantes en la Lista: como los monasterios de Haghpat y Sanahin en Armenia o el centro histórico de Salzburgo en Austria); ámbitos comarcales donde lo rural y lo natural ganan peso (paisajes culturales de la Lista como los de Gran Pré -Canadá- o el macizo Ennedi -Chad-; reservas de la biosfera como Jabal Moussa - Líbano - o Cévennes -Francia-; y geoparques como los de Kütralkura Chile- o Langkawi -Malasia-). A veces son espacios transnacionales (caso de la reserva de la biosfera del Delta del Río Senegal -Mauritania y Senegal-, el geoparque de Novohrad-Nógrád -Hungría y Eslovaquia - o el bien de la Lista Monte Perdido -España y Francia-); y tampoco faltan los ejemplos de enclaves espacialmente discontinuos (como los bienes en serie; por ejemplo, la Obra arquitectónica de Le Corbusier -Alemania, Argentina, Bélgica, Francia, India, Japón y Suiza-) o de configuraciones lineales en itinerarios culturales (como El Camino de Santiago) y corredores ecológicos (como la reserva de la biosfera de Togian Tojo Una-Una - Indonesia-).

Las escalas locales resultan básicas en el organigrama patrimonial de la Unesco. Son las depositarias y artífices de los recursos patrimoniales incluidos en sus listados y, también, las beneficiarias más inmediatas del prestigio y la dinámica económica asociada a estas distinciones. Aun así, la Unesco no ha desarrollado un entendimiento unitario de estas escalas y sus conceptuaciones y alcances varían según programas. Tampoco hay unidad en el tratamiento de la espacialidad interna de los bienes de los registros patrimoniales territorializados. El eje conceptual y el núcleo de sentido sobre el que gravita cada programa resultan claves a estos efectos: determinan el significado de la escala local en cada uno de ellos y establece las bases de sus zonificaciones internas (Tabla 4). 
Tabla 4. Las escalas locales en los programas patrimoniales territoriales de la Unesco

\begin{tabular}{|c|c|c|c|}
\hline & $\begin{array}{c}\text { CONVENCIÓN DEL } \\
\text { PATRIMONIO } \\
\text { MUNDIAL }\end{array}$ & PROGRAMA MAB & $\begin{array}{c}\text { PROGRAMA } \\
\text { INTERNACIONAL DE } \\
\text { CIENCIAS DE LA } \\
\text { TIERRA Y } \\
\text { GEOPARQUES }\end{array}$ \\
\hline $\begin{array}{l}\text { Ejes } \\
\text { conceptuales }\end{array}$ & $\begin{array}{l}\text { Valor (valor universal } \\
\text { excepcional) }\end{array}$ & $\begin{array}{l}\text { Función (conservación, } \\
\text { desarrollo y apoyo } \\
\text { logístico) }\end{array}$ & $\begin{array}{l}\text { Gestión y concepción } \\
\text { holística (confluencia } \\
\text { entre programas) }\end{array}$ \\
\hline $\begin{array}{l}\text { Núcleo de } \\
\text { atención / } \\
\text { sentido }\end{array}$ & Los bienes inscritos & $\begin{array}{l}\text { El territorio y las } \\
\text { poblaciones }\end{array}$ & $\begin{array}{l}\text { Las poblaciones y el } \\
\text { territorio }\end{array}$ \\
\hline $\begin{array}{l}\text { Zonificación } \\
\text { exigida }\end{array}$ & $\begin{array}{l}\text { - Zona núcleo (core } \\
\text { zone) } \\
\text { - Zona de } \\
\text { amortiguamiento } \\
\text { (buffer zone) }\end{array}$ & $\begin{array}{l}\text { - Zona núcleo } \\
\text { - Zona tampón } \\
\text { - Zona de transición }\end{array}$ & $\begin{array}{l}\text { No establece } \\
\text { zonificaciones }\end{array}$ \\
\hline
\end{tabular}

Fuente: elaboración propia

a) Las escalas locales en la Convención del Patrimonio Mundial

En la Convención el eje conceptual es el valor (o valor universal excepcional) y el núcleo de atención y sentido es el propio bien. El primero se define como "una importancia cultural y natural tan extraordinaria que trasciende las fronteras nacionales y cobra importancia para las generaciones venideras" (párrafo 49 de las Directrices Prácticas). Dicho valor universal excepcional recae sobre el bien, no necesariamente implica a los territorios y se expresa por el cumplimento de, al menos, uno entre diez criterios establecidos por las Directrices Prácticas (párrafo 77; Tabla 5). Seis de esos criterios son culturales y cuatro naturales; en caso de que el bien se inscriba por los criterios (i) al (vi) se califica como bien cultural; si responde a los criterios del (vii) al $(\mathrm{x}$ ) se registra como bien natural; y si combina ambos grupos de criterios se registra como bien mixto. Además de ello, el bien debe acreditar condiciones de autenticidad; esto es, debe transmitir de manera veraz y fehaciente su valor (Carta de Nara sobre la Autenticidad, 1994) - y de integridad, relacionada con su carácter completo e intacto o en el que sus transformaciones a lo largo de la historia no hayan afectado a su valor universal excepcional. 
Tabla 5. Criterios acreditativos del valor universa/ excepciona/en la Convención del

Patrimonio Mundial Cultural y Natural de la Unesco y atributos en los que se concreta

\begin{tabular}{|c|c|c|}
\hline \multicolumn{2}{|r|}{ CRITERIOS VUE } & ATRIBUTOS \\
\hline & $\begin{array}{l}\text { (i) Representar una obra maestra del genio creativo humano. } \\
\text { (ii) Testimoniar un importante intercambio de valores humanos a } \\
\text { lo largo de un periodo de tiempo o dentro de un área } \\
\text { cultural del mundo, en el desarrollo de la arquitectura o } \\
\text { tecnología, artes monumentales, urbanismo o diseño } \\
\text { paisajístico. } \\
\text { (iii) Aportar un testimonio único o al menos excepcional de una } \\
\text { tradición cultural o de una civilización existente o ya } \\
\text { desaparecida. } \\
\text { (iv) Ofrecer un ejemplo eminente de un tipo de edificio, } \\
\text { conjunto arquitectónico o tecnológico o paisaje, que ilustre } \\
\text { una etapa significativa de la historia humana. } \\
\text { (v) Ser un ejemplo eminente de una tradición de asentamiento } \\
\text { humano, utilización del mar o de la tierra, que sea } \\
\text { representativa de una cultura (o culturas), o de la interacción } \\
\text { humana con el medio ambiente [...]. } \\
\text { (vi) Estar directa o tangiblemente asociado con eventos o } \\
\text { tradiciones vivas, con ideas, o con creencias, con trabajos } \\
\text { artísticos y literarios de destacada significación universal } \\
\text { [...]. }\end{array}$ & $\begin{array}{l}\text { - Forma y diseño } \\
\text { - Materiales y } \\
\text { sustancia } \\
\text { - Uso y función } \\
\text { - Tradiciones } \\
\text { técnicas y sistemas } \\
\text { de gestión } \\
\text { - Localización, } \\
\text { emplazamiento y } \\
\text { entorno } \\
\text { - Lengua y otras } \\
\text { formas de } \\
\text { patrimonio } \\
\text { inmaterial } \\
\text { - Espiritualidad y } \\
\text { sensibilidad }\end{array}$ \\
\hline 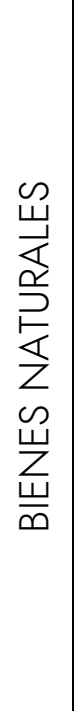 & $\begin{array}{l}\text { (vii) Contener fenómenos naturales superlativos o áreas de } \\
\text { excepcional belleza natural e importancia estética. } \\
\text { (viii) Ser uno de los ejemplos representativos de importantes } \\
\text { etapas de la historia de la tierra, incluyendo testimonios de } \\
\text { la vida, procesos geológicos creadores de formas } \\
\text { geológicas o [...geomorfológicas] significativas. } \\
\text { (ix) Ser uno de los ejemplos eminentes de procesos ecológicos } \\
\text { y biológicos en el curso de la evolución de los ecosistemas. } \\
\text { (x) Contener los hábitats naturales más representativos y más } \\
\text { importantes para la conservación de la biodiversidad, } \\
\text { incluyendo aquellos que contienen especies amenazadas } \\
\text { [...]. }\end{array}$ & $\begin{array}{l}\text { - Importancia visual o } \\
\text { estética } \\
\text { - Extensión de las } \\
\text { características físicas y } \\
\text { de los hábitats } \\
\text { naturales } \\
\text { - Vigencia y presencia } \\
\text { de los procesos físicos } \\
\text { o ecológicos } \\
\text { originarios } \\
\text { - Naturalidad, o carácter } \\
\text { intacto, de los sistemas } \\
\text { naturales } \\
\text { - Rareza y singularidad }\end{array}$ \\
\hline
\end{tabular}

Fuente: elaboración propia a partir de las Directrices Prácticas para la Aplicación de la Convención del Patrimonio Mundial (Unesco, 2019), parágrafos 77, 82 y 83

Todos estos criterios son muy generales y necesitan concretarse en atributos o rasgos específicos (Tabla 5). Estos difieren según se trate de bienes reconocidos por criterios culturales o naturales. Al margen de otros comentarios, quiere hacerse notar la poca consideración del territorio entendido en clave geográfica en esa relación de atributos. Este aparece de forma muy 
secundaria, fundamentalmente como dato básico de localización, emplazamiento y de entorno o atendiendo al carácter estético de las cuentas visuales. Las bases territoriales raramente se traducen en un valor específico del bien; a lo sumo actúan como realce en forma de proyecciones visuales o de otro tipo. La Convención asigna valor a bienes, pero no necesariamente ese valor implica a los territorios en los que se inscriben.

En la Convención todo gira en torno al bien: el valor universal excepcional; las condiciones de autenticidad e integridad y el plan de gestión que se exige a las candidaturas; hasta las zonificaciones internas, que son la expresión más genuina de espacialidad en estas escalas locales. A estos efectos, a los bienes se les exige la delimitación de dos áreas: a) la zona núcleo (o core zone), donde se condensa el valor universal excepcional y que, en término de gestión, es la parte del bien que necesariamente debe preservarse y b) envolviendo a la anterior se define la zona de amortiguamiento (o buffer zone), constituida por una o más áreas que no forman parte intrínseca del bien, pero que se consideran necesarias para la preservación y gestión de sus valores. La zona de amortiguamiento suele hacerse coincidir con el campo visual (o entorno) cuando este no forma parte de la zona núcleo del bien (como la Ópera de Sídney Australia-); otras veces abarca áreas espaciales más extensas, como una cuenca hidrográfica (Parque de los Tres Ríos Paralelos de Yunnan -China-); y, a menudo, tiene que ver con cualidades inmateriales (económicas, jurídicas, funcionales, ambientales, etc.) que refuerzan y respaldan el valor universal excepcional de la zona núcleo (Paisaje cultural y vestigios arqueológicos del valle de Bamiyán -Afganistán-).

Aunque la necesidad de contar con una cartografía precisa aparece desde el principio del desarrollo de la Lista, solo desde los primeros años de este siglo se ha reaccionado ante la falta de rigor o ausencia total de mapas o planos. El Comité del Patrimonio Mundial ha hecho llamamientos para que los distintos Estados corrigiesen esta situación y desde 2010 se ha avanzado mucho en completar y sistematizar la cartografía de los bienes que, como mínimo, debe mostrar con claridad las zonas núcleo y las de amortiguamiento. En algunos casos, como en los paisajes culturales, se concretan incluso sus escalas con un detalle, al menos, entre 1:25 000 y 1:50 000. Es esta una exigencia renovada, aunque muchos bienes aún carecen de esa cartografía precisa (con indefinición de escalas, ausencia de norte geográfico o leyendas ilegibles o inexistentes) o no tienen definidas zonas de amortiguamiento, como es el caso del núcleo histórico de Split (Croacia; Figura 4), muy expresiva del peso que ha ido adquiriendo el territorio en el marco de la Convención. Esto se añade a otras cuestiones ya señaladas, como la aparición de nuevas figuras de dimensión territorial como paisajes e itinerarios culturales. Aun 
así, la acepción de territorio que maneja la Convención, más centrada en el bien que en el propio territorio, genera demarcaciones extrañas como las del paisaje cultural del valle de Viñales (Cuba: Figura 5), de un formato geométrico ajeno a la sinuosidad divisoria propia de ríos, líneas de cumbres y otros componentes geográficos. Pero tampoco faltan ejemplos de delimitaciones bien ajustadas a las formas de territorios, particularmente en conjuntos históricos y bienes resultantes de la intervención humana como la muralla romana de Lugo o la ciudad histórica de Yazd (Irán; Figuras 6 y 7).

Figura 4. Núcleo histórico de Split (Croacia)

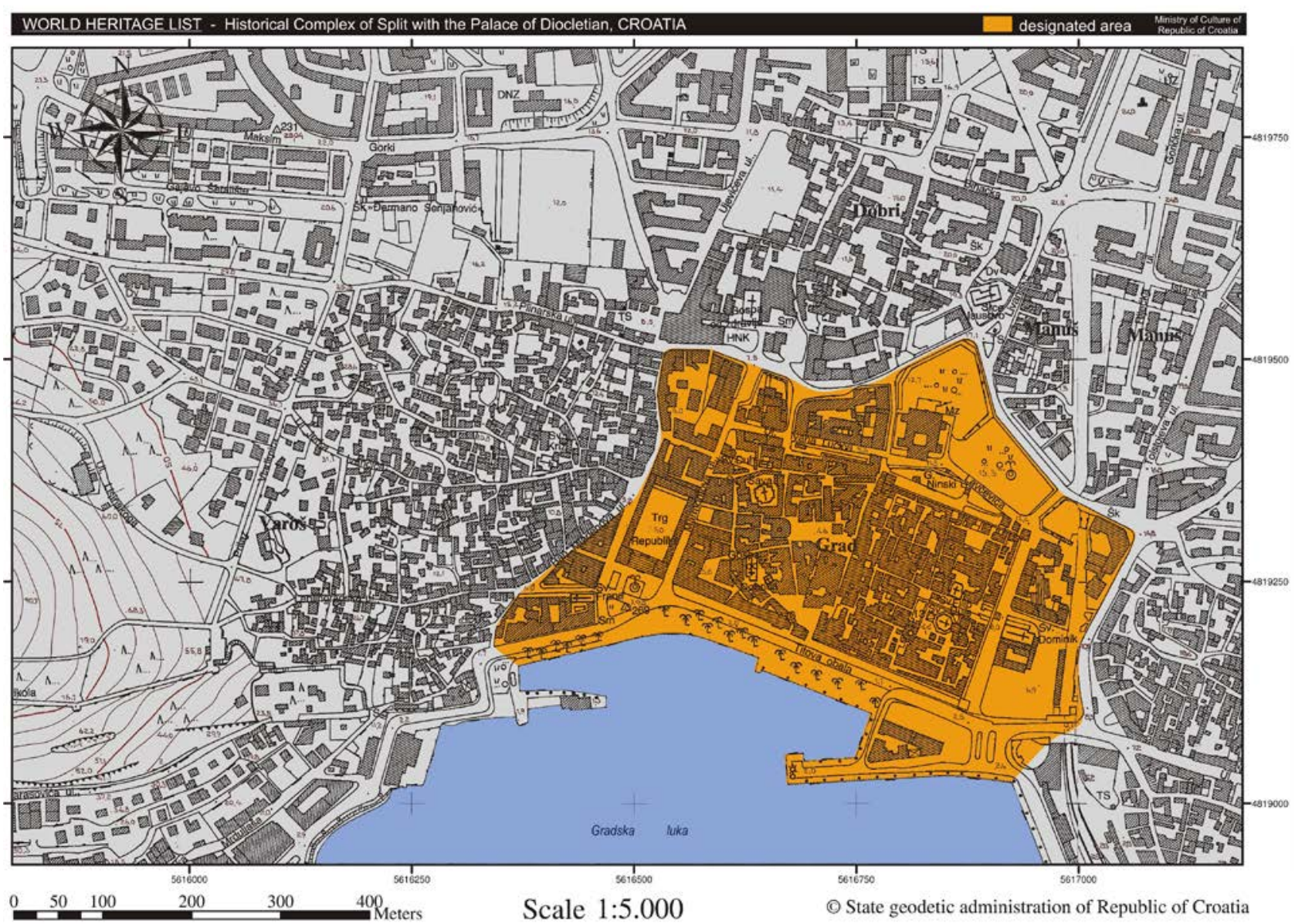

Fuente: State geodetic of Republic of Croatia (2008),

obtenida de la Lista del Patrimonio Mundial de la Unesco ${ }^{6}$ 
Figura 5. Valle de Viñales (Cuba)

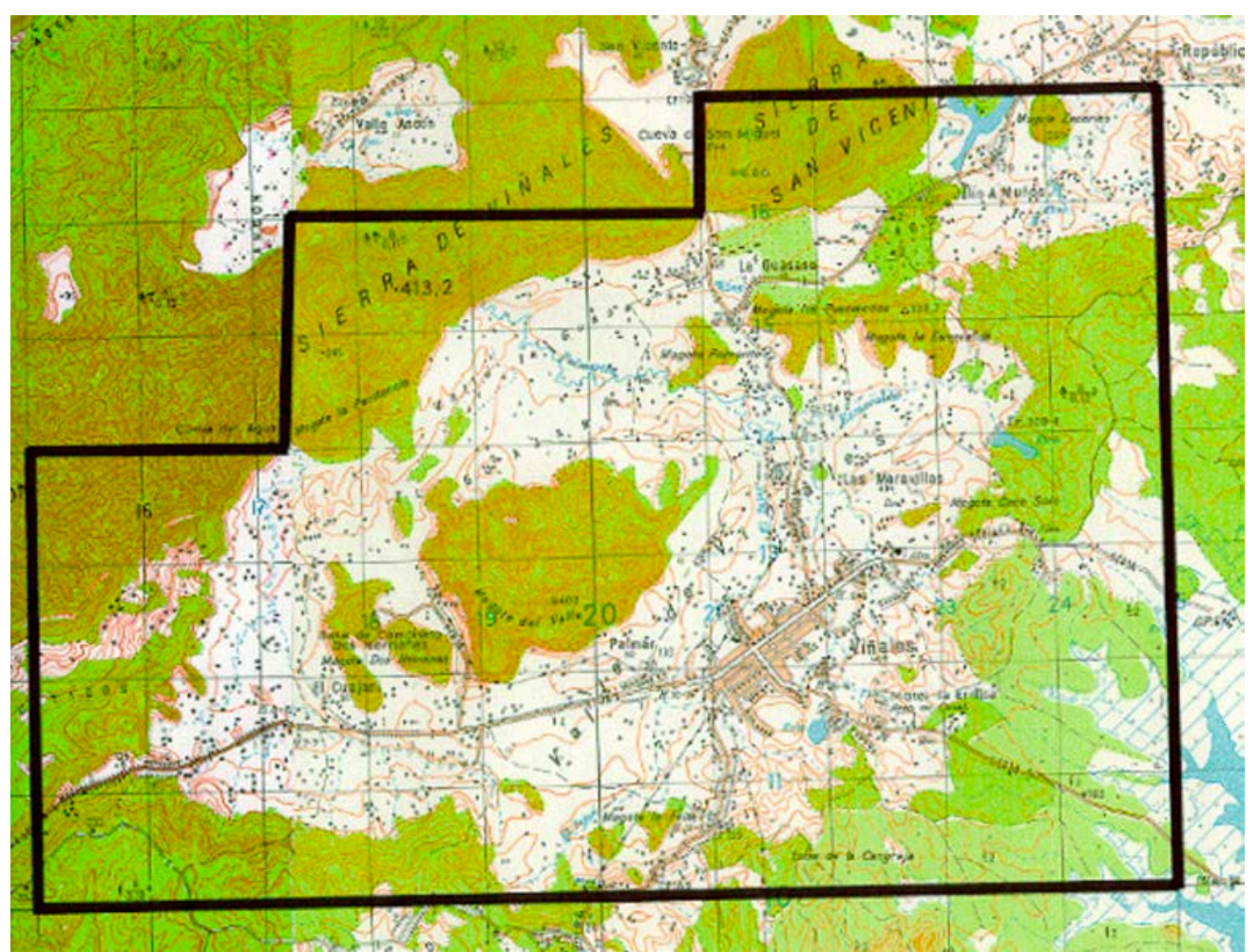

Fuente: n.a. (1998), obtenida de la Lista del Patrimonio Mundial de la Unesco ${ }^{7}$

Figura 6. Muralla romana de Lugo

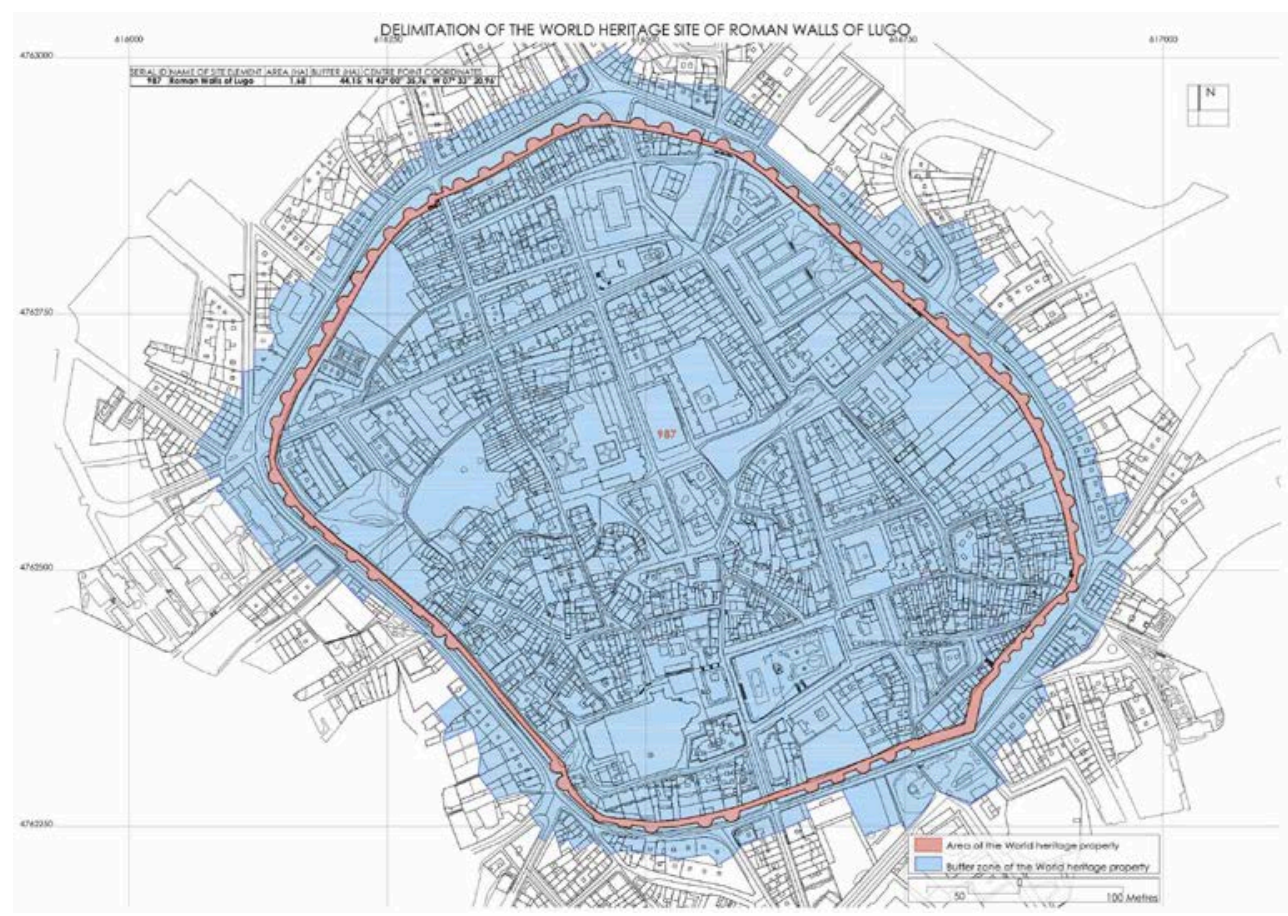

Fuente: n.a. (2000), obtenida de la Lista del Patrimonio Mundial de la Unesco ${ }^{8}$ 
Figura 7. Ciudad histórica de Yazd (Irán)

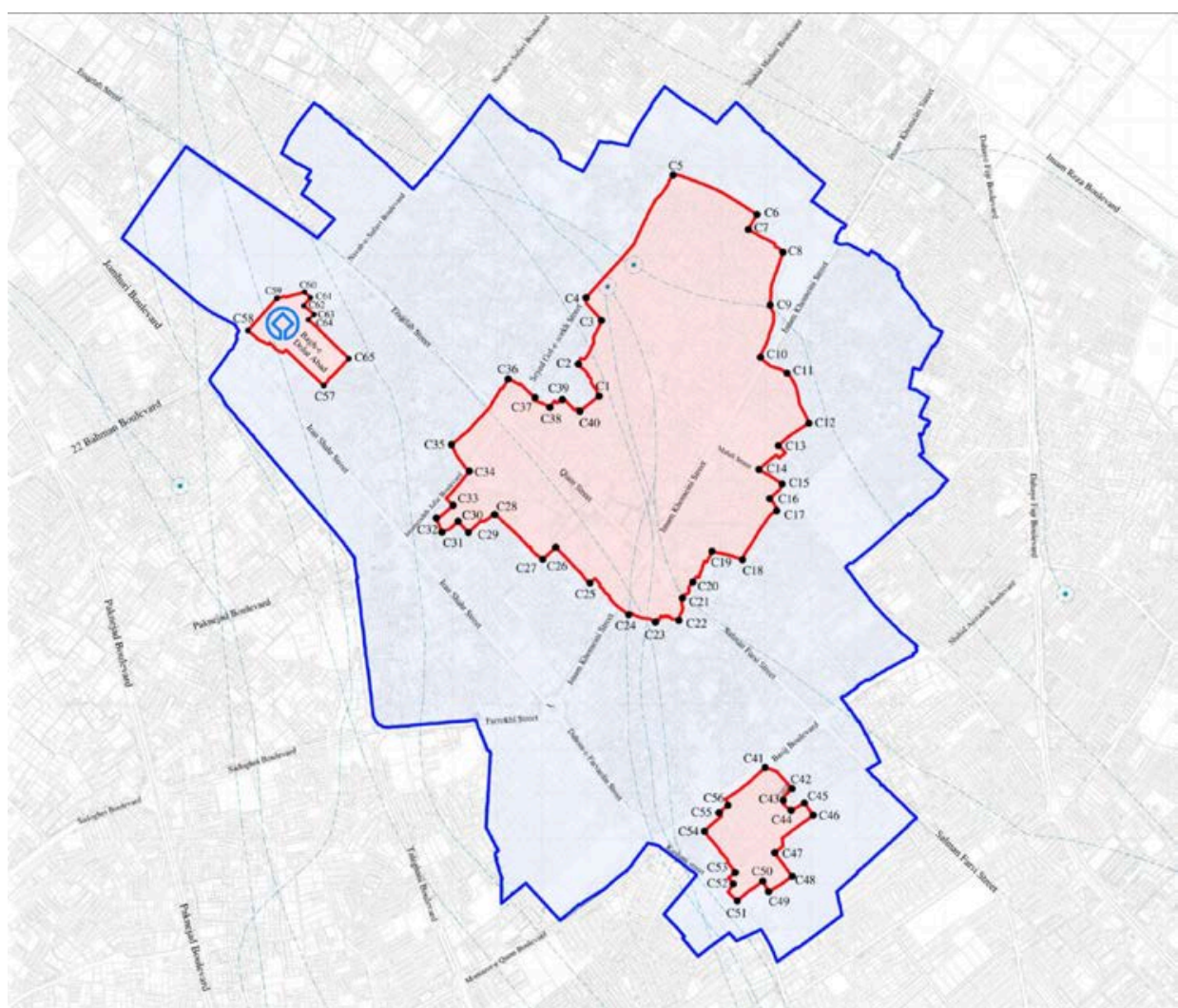

Fuente: n.a. (2017), obtenida de la Lista del Patrimonio Mundial de la Unesco 9

b) Las escalas locales en el programa MaB

El programa $\mathrm{MaB}$ enfoca el territorio en escalas locales de manera diferente y de forma más ajustada a las características del espacio en clave geográfica. El desplazamiento del meollo conceptual (del valor a la función) no es ajeno a ello y repercute en que, en el núcleo de sentido de este programa, los territorios son, en primer término, y las poblaciones que los habitan, de forma subsidiaria, los verdaderos protagonistas. Las reservas de la biosfera son lugares en los que, en concertación con las poblaciones locales, se conjugan:

[...] las ciencias exactas y naturales para mejorar los medios de subsistencia de las personas y preservar ecosistemas naturales u ordenados, promoviendo de esta manera planteamientos innovadores del desarrollo económico que sean adecuados desde el punto de vista social y cultural y sostenibles desde la óptica medioambiental" (Unesco, 2018-2019; s.p.).

8 Recuperada de https://whc.unesco.org/en/list/987/multiple=1\&unique_number=1151

9 Recuperada de https://whc.unesco.org/en/list/1544/multiple=1\&unique_number=2148 
A tal fin, su eje articulador es la función (o funcionalidades), sea esta de conservación, de desarrollo o de apoyo logístico. Las funciones se traducen en objetivos y estos, a su vez, se proyectan en espacios con características suficientes para satisfacerlos. El Marco Estatutario de la Red Mundial de Reservas de la Biosfera (establecido en 1995; Unesco, 1996), a la hora de fijar los criterios que ha de cumplir un espacio para ser aceptado como reserva de la biosfera, se refiere a ello de forma expresa, tanto en lo relativo a tener una dimensión suficiente, como en la obligatoriedad de realizar una zonificación interna: zona(s) núcleo, zona(s) tampón y zona exterior de transición (Tabla 6).

El formulario que han de cumplimentar las nuevas propuestas de reservas de la biosfera refuerza la cercanía de este programa al espacio geográfico al reconocer como ningún otro la complejidad interna e interrelacionada de las bases territoriales, los procesos de construcción histórica (traducidos en contextos socioeconómicos y culturales) y los marcos institucionales y normativos en los términos que maneja este trabajo (volver a Tabla 6; Unesco, 2013). En este caso y como exigencia a las candidaturas, se determinan parámetros, que no atributos como en el caso de la Lista. Este hecho hace que su precisión haya de ser más objetiva (dado que los atributos tienden a lo abstracto y menos objetivable) y son más fáciles de trasladar al territorio para comprenderlo con claves más geográficas.

c) Las escalas locales en el Programa Internacional de Ciencias de la Tierra y Geoparques

En el caso del Programa Internacional de Ciencias de la Tierra y Geoparques, su acepción de territorio en las escalas locales introduce una fuerte componente social en consonancia con el peso que tienen en él las comunidades que lo habitan; de ahí su núcleo de sentido: las poblaciones y sus territorios. El territorio es asumido como una extensión unitaria y sin subdivisiones: "Los geoparques mundiales de la Unesco son zonas geográficas únicas y unificadas en las que se gestionan sitios y paisajes de importancia geológica internacional con un concepto integral de protección, educación y desarrollo sostenible" (puntos 2.2 y 3 - párrafo i- de las Directrices Operativas para los Geoparques Mundiales de la Unesco). En los geoparques se hace más hincapié en la gestión de sus recursos (tanto en sus órganos gestores en otros agentes concernidos) y en su concepción integradora con otras declaraciones de la propia Unesco que en la determinación de sus territorios; aunque los geoparques deben estar claramente delimitados y con un tamaño adecuado a sus funciones y a la protección del patrimonio geológico (Tabla 7, criterio i). De hecho, en el programa existen pocas referencias explícitas más a la proyección espacial de los geoparques y estas solo se refieren a los 
procedimientos que se requieren para modificar su tamaño (parágrafos x, xi y xii del punto 5.6 de las Directrices Operativas).

\section{Tabla 6. Criterios, bases espaciales y parámetros exigibles}

\section{a las candidaturas a reservas de la biosfera}

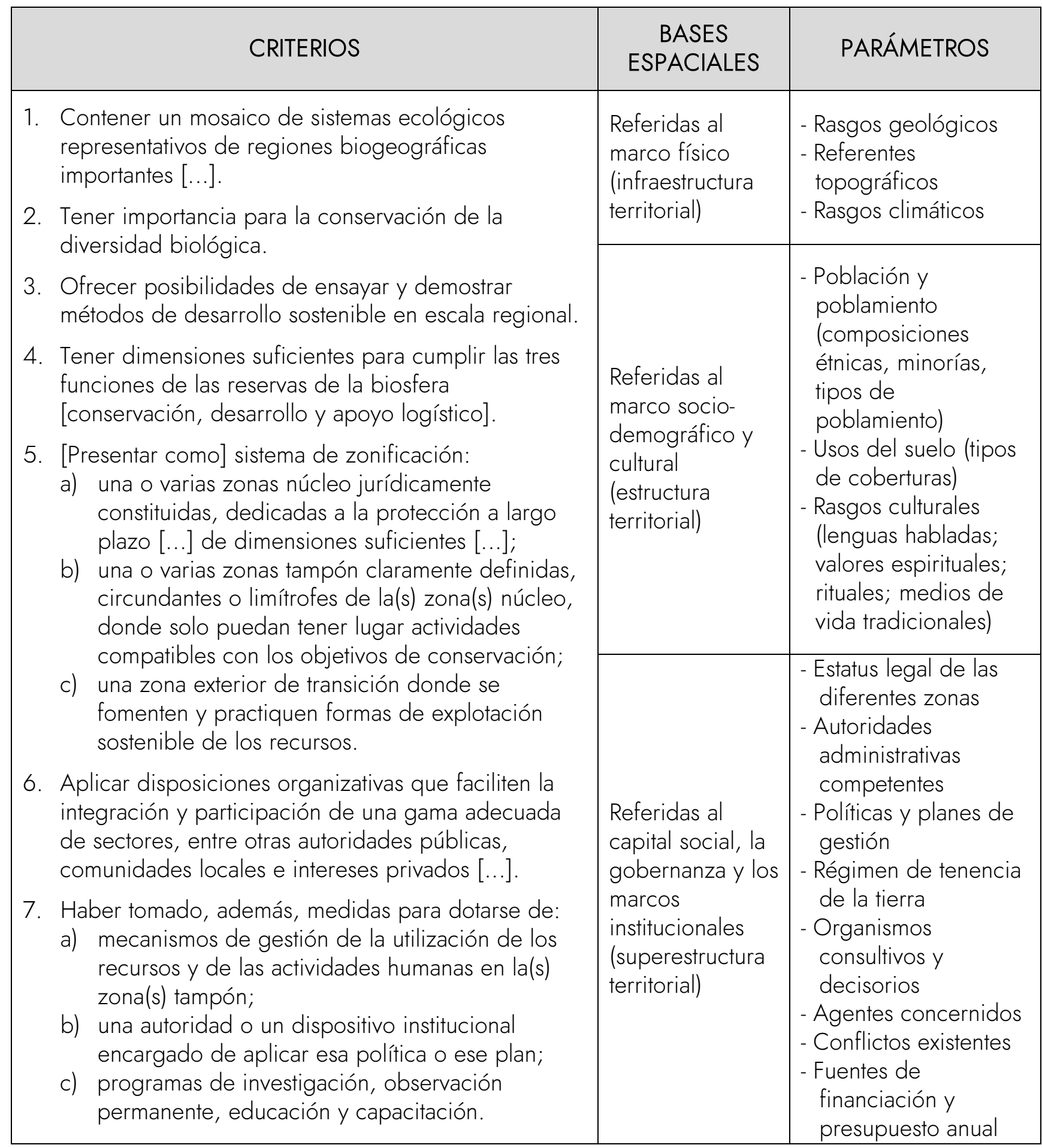

Fuente: elaboración propia a partir del artículo 4. del Marco Estatutario de la Red Mundial de

Reservas de la Biosfera y del formulario para la propuesta de nuevas reservas (Unesco, 2013) 


\section{Tabla 7. Criterios que deben cumplir los geoparques mundiales de la Unesco}

\section{CRITERIOS}

(i) Los geoparques [...] deben ser zonas geográficas únicas y unificadas en las que se gestionan sitios y paisajes de importancia geológica internacional con un concepto integral de protección, educación, investigación y desarrollo sostenible [..., debe[n] tener una frontera delimitada claramente, ser de tamaño adecuado para cumplir sus funciones y contener un patrimonio geológico de importancia internacional [...].

(ii) Los geoparques [...] deberían utilizar ese patrimonio, en conexión con todos los demás aspectos del patrimonio natural y cultural de esa zona, para promover [...] el incremento del conocimiento y la comprensión de: los procesos geológicos; los riesgos geológicos; el cambio climático; la necesidad de la explotación sostenible de los recursos naturales de la Tierra; la evolución de la vida y el empoderamiento de los pueblos indígenas.

(iii) Los geoparques [...] deberían ser zonas con un órgano de gestión que tenga existencia legal reconocida $[\ldots$ y] recursos adecuados $[. .$.$] .$

(iv) En caso de que una zona para la que se solicite la designación de geoparque [...] se solape con otro sitio designado por la Unesco, como un sitio del Patrimonio Mundial o una reserva de biosfera, la petición [...] habrá de aportar pruebas de cómo la condición de geoparque [...] añadirá valor tanto por la designación misma como en sinergia con las demás designaciones.

(v) Los geoparques [...] deberían hacer participar activamente a las comunidades locales y a los pueblos indígenas [...]. En asociación con [... ellos], se debe redactar y aplicar un plan de cogestión que atienda las necesidades sociales y económicas de las poblaciones locales, proteja el paisaje en que viven y conserve su identidad cultura [...].

(vi) Se alienta a los geoparques [0] a que compartan su experiencia y asesoramiento [...].

(vii) Un geoparque [...] debe respetar las leyes locales y nacionales relativas a la protección del patrimonio geológico. [... Los geoparques] deben estar protegidos jurídicamente antes de presentar una solicitud de designación. Al mismo tiempo, se debería utilizar un geoparque mundial de la Unesco de palanca para promover local y nacionalmente la protección del patrimonio geológico [...].

(viii) El cumplimiento de estos criterios se verificará por medio de listas de control con miras a la evaluación y la revalidación.

Fuente: Punto 3 de las Directrices Operativas

para los Geoparques Mundiales de la Unesco (Unesco, 2015)

En lo que a estructuración territorial interna de los geoparques se refiere (tan importante en la declaración de bienes de la Lista o de reservas de la biosfera), no se establece ningún requerimiento o disposición específica. Los criterios para la admisión en la red son muy generales, más relacionados con desideratas y objetivos y, en estas circunstancias, las características específicas del territorio se desdibujan y pierden virtualidad. Esa falta de concreción por parte de la Unesco viene a veces compensada por documentos requeridos por 
las instituciones nacionales que gestionan las candidaturas. Así, la Comisión Nacional Española de Cooperación con la Unesco señala en el anexo del documento orientador para solicitar su apoyo en la tramitación de estas candidaturas que estas deben incluir "un mapa detallado [... y] los criterios utilizados para la selección del perímetro, la superficie del territorio, adscripción administrativa (términos municipales incluidos) y una estimación de la población residente" (Punto 1. Anexo 1, Memoria para Solicitud de Carta de Apoyo de la Comisión Nacional Española de Cooperación con la Unesco para Candidaturas a Geoparques, s.f.).

\section{Discusión de los resultados}

\subsection{Discusión sobre el proceso metodológico y fuentes}

El concepto programas patrimoniales territoriales acuñado en este artículo ha resultado muy útil. Los dos criterios utilizados para seleccionar tales programas (que generen listas o registros espacialmente referenciados y que estas referencias se expliciten a través de técnicas cartográficas) han sido muy clarificadores. Entre otros resultados, han llevado a desestimar algunos programas inicialmente considerados, como la Convención para la Salvaguardia del Patrimonio Cultural Inmaterial que, si bien establece tres listados, a sus registros no se les exige expresión cartográfica alguna. Es esta una aportación no menor que pone en entredicho el hecho de acudir habitualmente al patrimonio inmaterial o etnográfico como referente de territorialidad y la consiguiente y frecuente asimilación entre ambos tipos de patrimonio (territorial y etnográfico). El criterio metodológico seguido en este trabajo ha dado en ceñirse a los tres programas estudiados: la Convención, el Programa MaB y el Programa Internacional de Ciencias de la Tierra y Geoparques.

El reconocimiento de la complejidad del concepto territorio, en sus distintas acepciones y escalas, y la distinción entre el territorio entendido como espacio político-administrativo, por una parte, y como espacio en términos geográficos, por otra, también han resultado muy útiles.

Con relación a las fuentes, pese a que no faltan enlaces de interés, se ha podido comprobar que las alusiones al espacio por parte de la Unesco están en buena parte encriptadas y ha habido que descifrarlas. Ello ha requerido un estudio de carácter hermenéutico de convenciones, dictámenes y documentos. El acceso a los listados de bienes, reservas y geoparques tampoco ha estado exento de problemas (duplicidades, dificultad en hallar registros, traducciones equívocas, etc.); cabe pues concluir que la Unesco no es todo lo sistemática que sería deseable desde el interés geográfico en la información territorializada que aporta. La tarea se vuelve más compleja cuando se pretende comparar datos de distintos 
programas entre sí, ya que cada uno ha nacido de coyunturas, sensibilidades y concepciones científicas dispares; y ello se traduce en asunciones diferentes del significado del territorio y de sus formas de asignarle atributos e información, tanto cuantitativa como cualitativa. Todo ello confirma la oportunidad de este artículo respecto a la necesidad de establecer mínimos comunes denominadores entre programas que permitan analizar sus bienes, reservas y geoparques con correspondencias ajustadas y fiables.

\subsection{Discusión sobre la incorporación del territorio al acervo patrimonial de la Unesco}

El análisis comparado de los programas patrimoniales territoriales es en sí mismo una aportación de este artículo habida cuenta de la escasez de estudios que los analicen de manera conjunta. El cotejo analítico entre ellos ha resultado muy enriquecedor y ha permitido abundar en las distintas vías a través de las cuales está teniendo lugar el acercamiento del patrimonio al territorio en el seno de la Unesco. A saber:

- A través de las transversalidades entre programas patrimoniales, a su vez con distintas expresiones: a) aproximaciones y mescolanza entre patrimonio cultural y natural; b) confluencias de finalidades, particularmente en lo que tiene que ver con la apuesta de todos ellos por la utilización de los bienes, reservas y geoparques como recurso para el desarrollo de los territorios; c) permeabilidades en cuanto a valores, reflejada, por ejemplo, en la cercanía de los criterios de valor universal excepcional del vii al x exigidos a los bienes de la Lista y las cualidades propias de las reservas de la biosfera y de los geoparques mundiales.

- A través de los procesos de patrimonialización y de los agentes principales de cada programa: a) predominio de la patrimonialización de "arriba abajo", especialmente de los Estados como entes protagonistas en la Convención; b) una suerte de patrimonialización mixta entre Estados y comunidades locales, con un peso importante de estas últimas en el caso las reservas de la biosfera, que es precisamente en donde el territorio en clave geográfica aparece con más nitidez; y c) patrimonialización de base social, o de "abajo arriba", con las comunidades locales como actores cardinales de los geoparques. Tal diversidad de escalas, actores y procesos constituye un exponente irrefutable de la territorialidad de esos programas. No obstante, el hecho de que algunas propuestas de estas candidaturas partan desde los territorios no significa que se eliminen recelos y problemas a la hora de tramitarlas. Como ejemplo podrían señalarse las fallidas iniciativas por recelos municipales a las posibles cortapisas que impondría su aceptación (especialmente de carácter urbanístico) de la Alpujarra a la Lista (alentada por las diputaciones de Granada y Almería y rechazada por 
numerosos alcaldes de la zona en 2014) o la de los valles pasiegos como reserva de la biosfera (impulsada en 2015 por la Asociación para el Desarrollo de los Valles Pasiegos y en la que algunos municipios se opusieron a integrarse en el área inicialmente propuesta y esto llevó a que el Comité Español del programa MAB informase negativamente el conjunto de la propuesta en 2019 y a que en 2020 se plantee una nueva y más que dudosa candidatura sin los municipios de Vega de Pas y San Pedro).

- A través de la emergencia de figuras patrimoniales nuevas en las que el territorio adquiere categoría patrimonial sustantiva, aunque con diferencias notables según programas. La Convención empezó concibiendo los bienes de la Lista al margen de los espacios en los que se insertaban y luego se ha territorializado progresivamente a tenor de la evolución operada en la conceptuación del patrimonio cultural: desde su asimilación inicial a obra de arte (cuya proyección en el espacio es meramente puntual), a la consideración patrimonial de bienes que se expresan sobre todo a través de líneas (canales históricos o itinerarios culturales) y áreas (conjuntos históricos, paisajes culturales, paisajes urbanos históricos, etc.). Las reservas de la biosfera y los geoparques han tenido desde sus inicios una identificación espacial de carácter zonal y su calado territorial es desde sus orígenes más potente.

- En estrecha relación con lo anterior, y en lo que tiene que ver con las bases de las alianzas patrimonio-territorio, está la evolución operada desde el entendimiento del territorio como contendor de bienes patrimoniales (donde el territorio es un mero escenario), pasando por la acepción de territorio-patrimonio (en la que el territorio adquiere categoría patrimonial sustantiva), hasta llegar a la condición de territorio receptor de programas patrimoniales en una concepción nueva de instrumentación del patrimonio y del territorio como proyecto patrimonial, en buena parte todavía sin explorar.

- A través del territorio asumido como la extensión propia y precisa de cada bien, con grandes diferencias en cuanto a dimensión de los bienes en los distintos programas: con elevados contrastes en los bienes de la Lista (desde menos de un área a superar las 40000 ha); con espacios relativamente extensos (una media de 929000 ha) en las reservas de la biosfera; y con ámbitos de extensión media más reducida (en torno a las 1775 ha) en los geoparques. Esa acepción de territorio entendido como extensión, lejos de constituir una aproximación meramente descriptiva y banal, tiene una trascendencia importante para la conservación y gestión de los bienes patrimoniales y para la determinación de los instrumentos necesarios para su consecución. Dicho de otra manera, la preservación y la gestión patrimonial adquieren significados diferentes dependiendo, no solo de las lógicas y dominantes 
territoriales propias de cada programa, sino de la extensión o amplitud superficial de sus bienes.

\subsection{Discusión sobre la visión escalar de los programas patrimoniales de la Unesco}

La vocación de la Unesco es la escala planetaria, pero los objetivos de sus grandes programas patrimoniales (que se pueden sintetizar en identificación, protección y gestión) se aplican a la escala local. En consecuencia, se pueden obtener conclusiones diferenciadas:

a) Respecto a la escala global:

Este trabajo reivindica la necesaria recuperación de la escala planetaria en los análisis propios de las investigaciones geográficas. La mundialización de las pautas culturales, de la economía y del propio patrimonio abocan a ello. En lo que respecta a los programas patrimoniales territoriales de la Unesco, ello es particularmente necesario ya que, en tanto que organización internacional, el referente espacial natural de la Unesco es la escala global. Sin embargo, la organización no ha desarrollado una lectura unitaria del patrimonio a escala internacional y el mapamundi del patrimonio está en cierta medida por hacer, al menos con una verdadera coherencia espacial, tanto dentro de cada programa analizado como entre los distintos programas entre sí. Ello no significa que la Unesco no se haya ocupado o mostrado interés por el territorio a esta escala global; se trata de que no ha proyectado una mirada unitaria y firme y que, cuando sus programas incorporan el territorio a esta escala, lo hacen desde diferentes perspectivas, aunque principalmente desde dos: a través de una división del planeta propia de la Unesco, que lo organiza en cinco regiones y que deja al margen la Antártida, y a través de los reinos biogeográficos, que sí incluyen el extremo austral. La primera rige en la aceptación de nuevos bienes en la Lista; la segunda es utilizada en bienes y programas sobre patrimonio natural, fundamentalmente en lo concerniente al Programa Mab.

Se trata de dos regionalizaciones muy diferentes en cuanto a conceptuaciones, alcance y organización espacial. La primera, propia de la Unesco y que divide el planeta en cinco grandes regiones, no se rige por criterios claramente establecidos, más allá de un pretendido reparto equitativo de los bienes entre continentes y culturas (reparto muy discutible desde el punto de vista del espacio geográfico y muy fácil de instrumentalizar desde lo político). Ello no resta protagonismo a estas regiones, y mucho menos practicismo en un organismo (recuérdese que se enmarca en las Naciones Unidas) de ententes políticos frágiles y cambiantes y, no menos importante, con capacidades científico-técnicas entre Estados muy diferentes para elaborar candidaturas a los programas de la Unesco. En algunos de ellos, sobre todo en la Lista, estar en 
una región u otra del planeta se convierte en un hecho competitivo o requisito determinante para la aceptación de candidaturas, o lo contrario.

La segunda regionalización se define por los reinos biogeográficos y responde a criterios científicos (con especial referencia a la aportación hecha ex profeso para el Programa Mab por Miklos Dezso Ferenc Udvardy) y su sentido es preferentemente valorativo; esto es, se recurre a ella como argumento acreditativo de valor en las candidaturas.

La Unesco es una organización eminentemente política y ve el territorio en esos términos. Por ello, si bien utiliza los reinos y provincias biogeográficas, lo hace en un plano secundario y, como se ha mencionado, con una intención meramente analítica. En caso de conflicto entre la mirada política y la técnico-científica, prevalece la primera. Así, por ejemplo, las candidaturas de lugares a la Lista por criterios naturales recurren a menudo a la regionalización biogeográfica como argumento acreditativo de valor, pero, para su postulación, se pondera la región a la que se adscriben los Estados que las presentan.

b) Respecto a las escalas locales:

La Unesco tampoco ha desarrollado un entendimiento unitario de estas escalas y cada programa las entiende de manera diferente. Su análisis comparado según programas a partir de las nociones de eje conceptual y núcleo de sentido acuñadas en este trabajo ha permitido avanzar en el análisis de la distinta consideración del territorio en ellas a través, aunque no solo, de las zonificaciones internas propias de cada programa.

Con carácter general, cabe concluir que estas escalas locales expresan mejor el territorio entendido como espacio geográfico en todos sus significados, pero con importantes diferencias según los programas. La Convención es la que peor entiende y formula ese territorio. En ella todo gira en torno al bien (el valor universal excepcional, las zonificaciones internas, las condiciones de autenticidad e integridad y el plan de gestión). El territorio ciertamente ha ganado peso en ella, pero en un plano todavía secundario. Las bases territoriales raramente se plasman como un argumento o valor intrínseco (con excepciones en algunos paisajes culturales y espacios naturales) y, a lo sumo, son concebidas para realzar el bien (como potenciador de sus perspectivas paisajísticas o de otro tipo). El resultado de ello, a menudo, son delimitaciones zonales imperfectas o al menos mal sustentadas. En el otro extremo, el Programa MaB es, de los tres analizados, el que más se aproxima al entendimiento del territorio en clave geográfica: como una simbiosis entre bases naturales (a modo de infraestructura territorial o esqueleto), unos procesos de construcción histórica (la estructura territorial) y unas dinámicas de apropiaciones 
sociales e institucionales, reflejadas en leyes, normas y referentes identitarios (superestructura territorial). La Red de Geoparques Mundiales, por su parte, se vuelca hacia el desarrollo local a partir, sobre todo aunque no solo, de su patrimonio geológico. El territorio está presente, pero de manera difuminada ya que el interés se dirige a sus agentes. Los geoparques mundiales proyectan la acción de esos agentes, su modelo de desarrollo y su concepción holística de los recursos de la zona. Ciertamente el territorio se concibe como un escenario mucho más cercano a los intereses de sus habitantes (de los que por lo menos se tiene la certeza de que conocen bien su territorio, sus potencialidades y limitaciones), pero no es el territorio con toda la coherencia y significado que le exige la doctrina geográfica. Aunque, quién sabe, tal vez en este planteamiento de modelos de desarrollo con objetivos y métodos que deben ser revisados periódicamente y con una permanencia en la red no asegurada ad infinitum será en estos geoparques donde se produzca un retorno del patrimonio a los territorios más justo y sostenible. Habrá que esperar a que se conozca la evolución de este programa en el plazo de unos años.

c) Respecto al papel de los Estados

El mayor protagonismo del territorio geográfico en las escalas locales, con las precisiones antedichas, no puede obviar que los proponentes directos de los bienes ante la Unesco son los Estados, que firman y ratifican los programas, y que ello implica la prioridad del territorio político sobre el geográfico; también en estas escalas. La paradoja se produce cuando, siendo universal el espíritu de la Unesco y local su ámbito de aplicación, es en el marco político intermedio de estos Estados en el que se dirime la mayor parte de, por no decir todas, las responsabilidades y cuitas. La consecuencia es que ninguno de los programas patrimoniales territoriales de la institución responde de forma coherente a una perspectiva espacial planetaria, compleja y generosa. $O$, en otras palabras, la Unesco nunca podrá alcanzar los objetivos de sus programas globales en tanto que el territorio en el que se mire venga a ser un espejo deformado, cuando no retorcido, por el contexto político-administrativo mundial.

\section{Corolario conclusivo}

En este artículo se ha reflexionado sobre la presencia y significado del territorio en los programas patrimoniales de la Unesco desde la lógica de la propia organización, que no necesariamente es la misma que la que se plantea desde los territorios, más centrada en los cambios, repercusiones y ventajas de adherirse a esos programas (de todo tipo, pero principalmente económicos). La evolución operada en el campo del patrimonio en lo que atañe a su aproximación al territorio y la falta de explicitación de las bases de ese arrimo alentaban su 
indagación desde el marco de una organización internacional protagonista en esos cambios como la Unesco. La reivindicación de las virtualidades del patrimonio como motor de desarrollo de los territorios, repetidamente aludida y raramente demostrada, junto a la escasez de estudios que confirmen - de forma nítida, fehaciente y replicable- en qué ámbitos y circunstancias el patrimonio coadyuva al desarrollo de los territorios, también impulsaban esa línea. El cambio de enfoque en la forma de encarar el trinomio patrimonio-territorio-desarrollo a través del análisis de las lógicas territoriales de los programas es una aportación original de este artículo.

La progresiva inclusión del territorio en el acervo patrimonial de la Unesco se ha operado de manera dual, tanto en lo que tiene que ver con las escalas consideradas (global y local), como con la forma con que en ellas se proyecta. El predominio del territorio en clave política por el peso de los Estados es claro, particularmente en la escala planetaria, pero la forma de entender este con claves geográficas más generosas se está abriendo paso a través de las escalas locales. Que la Unesco se ha puesto el filtro del territorio en las gafas, eso no puede dudarlo nadie; que los cristales estén bien graduados, sí. Una lectura e interpretación correcta de las invariantes territoriales puede aportar mucho en el empeño de que los enfoques sobre el espacio mejoren y sean beneficiosos para los tres programas patrimoniales de la Unesco, tanto por separado, como en su inevitable confluencia. A esto podría añadirse que en un mundo global en el que las Naciones Unidas, además de la Unesco, tiene o colabora con otras agencias y programas de tanta o mayor importancia que esta, espacialmente en épocas de catástrofes sanitarias, económicas y sociales (el Alto Comisionado de las Naciones Unidas para los Refugiados ACNUR-; el Fondo de las Naciones Unidas para la Infancia -Unicef-; la Organización Mundial de la Salud _OMS-; la Organización de las Naciones Unidas para la Alimentación y la Agricultura -FAO_; etc.), los riesgos de trabajar con bases territoriales desenfocadas pueden ser, y de hecho lo son con frecuencia, muy graves. Más que nunca la geografía, desde su mirada inter escalar, rica y compleja de los territorios, puede ser útil para proponer diagnósticos ajustados, directos y certeros que ayuden a tomar decisiones en las distintas instancias políticas internacionales que, a través de un buen, profundo y justo conocimiento del espacio, aporten soluciones a los grandes conflictos, nuevos y viejos, de la humanidad.

Declaración responsable: Las/os autoras/es declaran que no existe ningún conflicto de interés con relación a la publicación de este artículo. Las tareas se han distribuido de la siguiente manera: el artículo ha sido coordinado al unísono por las/os dos autoras/es. Ambas/os han 
participado en la revisión bibliográfica, en la elaboración delas tablas y figuras y en la redacción del artículo. 


\section{Bibliografía y otras referencias}

Alonso Hierro, J.A., \& Martín Fernández, J. (2013). Activos culturales y desarrollo sostenible: La importancia económica del Patrimonio Cultural. Política y Sociedad, 50(3), 11331147. https://doi.org/10.5209/rev_POSO.2013.v50.n3.41861

Baraja Rodríguez, E., García de Celis, A.J., \& Herrero Luque, D. (2019). Gestión del paisaje vitivinícola en las reservas de la biosfera españolas. Cuadernos Geográficos, 58(3), 145-168. Retrieved from https://revistaseug.ugr.es/index.php/cuadgeo/article/view/8637

Benito del Pozo, P. (2002). Patrimonio industrial y cultura del territorio. Boletín de la Asociación de Geógrafos Españoles, 34, 213-227. Retrieved from hittp://bage.agegeografia.es/ojs/index.php/bage/article/download/437/408

Bertacchini, E.E., \& Saccone, D. (2012). Toward a political economy of World Heritage. Journal of Cultural Economics, 36(4), 327-352. https://doi.org/10.1007/s10824-012-9169-3

Bortolotto, C. (2014). La problemática del patrimonio cultural inmaterial. Culturas. Revista de Gestión Cultural, 1(1), 1-22. Retrieved from

https: $/ /$ www. google.com/url? sa=t\&rct=j\&q=\&esrc=s\&source=web\&cd=3\&ved=2ahUKEwjHh8 e155rpAhWKAWMBHYYaCqYQFjACegQ|AxAB\&url=https\%3A\%2F\%2Fpolipapers.upv.es\%2Find ex. php\%2Fcs\%2Farticle\%2Fdownload\%2F3162\%2F3610\&usg=AOvVaw13cj0389CYd5iOZZGOw $\underline{\text { F84 }}$

Brunel, M.C. (2008). Poner la conservación al servicio de la producción campesina, reto para la construcción de un nuevo paradigma de desarrollo. Argumentos (México, DF), 21(57), 115-139. Retrieved from http://www.scielo.org. $\mathrm{mx} /$ scielo.php? script=sci_arttext\&pid=S0187$\underline{57952008000200006}$

Caravaca, I., Colorado, D., Fernández, V., Paneque, P., \& Puente, R. (1996). Patrimonio cultural y desarrollo regional. Revista EURE-Revista de Estudios Urbano Regionales, 22(66), 89-99. Retrieved from http://www.eure.cl/index.php/eure/article/view/1134

Castillo Ruiz, J. (1997). El entorno de los bienes de inmuebles de interés cultural. Concepto, legislación y metodología para su delimitación. Granada: Universidad de Granada.

Centro Internacional para las Reservas de la Biosfera Mediterráneas (n.d.). Centro Internacional para las Reservas de la Biosfera Mediterráneas. Retrieved from https://www.unescomedcenter.org/es/centro-unesco 
Centro del Patrimonio Mundial (n.d.). World Heritage List. En CPM. Retrieved from https://whc.unesco.org/en/list/

Cid Carmona, S. (2009). 40 años del Programa MaB de la Unesco. Isagogé, 6, 27-31. Retrieved from http://isagoge.atspace.com/documentos/Archivo_isagogeb/40_AGNOS_DEL_PROGRA MA_MaB_UNESCO.pdf

Climent-López, E., \& Esteban-Rodríguez, S. (2018). Paisaje y patrimonio territorial en las Denominaciones de Origen vinícolas del Valle del Ebro (España). In XII Congreso Internacional Terroir. E3S web conf (50, 01046). https://doi.org/10.1051/e3sconf/20185001046

Comisión Nacional Española de Cooperación con la Unesco (n.d.). Documentación a aportar por los territorios aspirantes a geoparques para solicitar la carta de apoyo de la comisión nacional española de cooperación con la Unesco. CNECU. Retrieved from http://www.igme.es/patrimonio/DOCUMENTO_ASPIRANTES_GEOPARQUES_COMISIO N2014.pdf

Consejo de Europa (2005). Council of Europe Framework Convention on the Value of Cultural Heritage for Society. C.E. Retrieved from https://www.coe.int/en/web/conventions/full-list//conventions/rms/0900001680083746

Criado-Boado, F., \& Barreiro, D. (2013). El patrimonio era otra cosa. Estudios atacameños, 45, 5-18. http://dx.doi.org/10.4067/S0718-10432013000100002

Deegan, N. (2012). The local-global nexus in the politics of World Heritage: Space for community development? Community development through World Heritage. In M.-T. Albert, M. Richon, M.J. Viñals \& A. Witcomb (Eds.), Community Development Through World Heritage (7783). Paris: Unesco. Retrieved from

https://www.academia.edu/download/38671817/publi_wh_papers_31_en.pdf\#page=78

Dormaels, M. (2012). Identidad, comunidades y patrimonio local. una nueva legitimidad social. Alteridades, 22(43), 9-19. Retrieved from

http://www.scielo.org.mx/scielo.php?pid=S0188-70172012000100002\&script=sci_arttext

Estenssoro, F. (2015). El ecodesarrollo como concepto precursor del desarrollo sustentable y su influencia en América Latina. Universum (Talca), 30(1), 99. http://dx.doi.org/10.4067/S0718-23762015000100006

Fernández Cacho, S. (2019). La dimensión paisajística en la gestión del patrimonio cultural en España. Estudios Geográficos, 80(287). https://doi.org/10.3989/estgeogr.201943.023 
Fernández Salinas, V. (2013). De dónde y hacia dónde. Perspectivas y premisas para el entendimiento de los itinerarios culturales. Biblio 3W, XVIII(1028). Retrieved from http://www.ub.edu/geocrit/b3w-1028.htm

Fernández Salinas, V., \& Silva Pérez, R. (2016). Deconstruyendo los paisajes de la Lista del Patrimonio Mundial de la Unesco. Cuadernos Geográficos, 55(1), 176-197. Retrieved from https://revistaseug.ugr.es/index.php/cuadgeo/article/view/3429

Forrest, C. (2010). International law and the protection of cultural heritage. London: Routledge.

Francioni, F., \& Lenzerini, F. (2008). The 1972 World Heritage Convention. A Commentary. Oxford (UK): Oxford University Press.

Gómez Mendoza, J. (2013). Del patrimonio-paisaje a los paisajes-patrimonio. Documents d'Anàlisi Geogràfica, 59(1), 5-20. https://doi.org/10.5565/rev/dag.48

González-Tejada, C., Du, Y., Read, M., \& Girault. Y. (2017). From nature conservation to geotourism development: Examining ambivalent attitudes towards UNESCO directives with the global geopark network. International Journal of Geoheritage, 5(2), 1-20. Retrieved from https://halshs.archives-ouvertes.fr/halshs-02087621/document

Graham, B.; Ashworth, G. y Tunbridge, J. (2016). A Geography of Heritage. Power, Culture and Economy. London (UK): Routledge.

Gurrutxaga San Vicente, M., \& Porcal Gonzalo, M.C. (2019). Análisis de los retos de gestión del paisaje del Bien Pirineos-Monte Perdido tras dos décadas inscrito en la Lista del Patrimonio Mundial de Unesco (1997-2018). Investigaciones Geográficas, 71, 75-

96. https://doi.org/10.14198/INGEO2019.71.04

Henriques, M.H., \& Brilha, J.B. (2017). UNESCO Global Geoparks: A strategy towards global understanding and sustainability. Episodes, 40(4), 349-

355. http://dx.doi.org/10.18814/epiiugs/2017/v40i4/017036

Hernández Ramírez, J. (2011). Los caminos del patrimonio. Rutas turísticas e itinerarios culturales. Pasos. Revista de Turismo y Patrimonio Cultural, 9(2), 225-236. Retrieved from https://www.redalyc.org/pdf/881/88117284001.pdf

Iglesias Skuli, A. (2011). La protección de la ordenación del territorio, el patrimonio histórico y el medio ambiente en la sociedad del riesgo. In P. Faraldo-Cabana \& L.M. Puente Alba (Coords.), Ordenación del territorio, patrimonio histórico y medio ambiente en el código penal y la legislación especial (pp. 19-34). Valencia: Tirant Lo Blanch. 
Isar, Y.R. (2011). Unesco and heritage: Global doctrine, global practice. In H. Anheier e Isar, Y.R. (Eds.), Heritage, Memory \& Identity (pp. 39-52). Los Angeles (US): Sage.

Jaeger, T. (2005). Nuevas perspectivas para el programa MAB y las reservas de Biosfera. Lecciones aprendidas en América. Paris / Montevideo: Unesco / Programa de Cooperación SurSur, 35. Retrieved from

https://www.researchgate.net/profile/Tilman_laeger/publication/242582252_NUEVAS_PERS PECTIVAS_PARA_EL_PROGRAMA_MAB_Y_LAS_RESERVAS_DE_BIOSFERA/links/546694380cf 2397f7829dd5a/NUEVAS-PERSPECTIVAS-PARA-EL-PROGRAMA-MAB-Y-LAS-RESERVAS-DE-

\section{BIOSFERA.pdf}

King, V.T. (2016). World Heritage in Southeast Asia: Issues, Prospects and Problems. Copenhague (Denmark): Nordic Institute of Asian Studies (NIAS).

López-Guzmán, T., \& Jesus, M.M. (2011). Turismo, cultura y gastronomía. Una aproximación a las rutas culinarias. Tourism \& Management Studies, 1, 929-922. Retrieved from https://www.redalyc.org/pdf/3887/388743867083.pdf

Lorusso, S., Cogo, G. M., \& Natali, A. (2017). The protection and valorization of cultural and environmental heritage in the development process of the territory. Conservation Science in Cultural Heritage, 16(1), 59-88. Retrieved from https://conservationscience.unibo.it/article/view/7165

Martínez Arnaiz, M., Baraja Rodríguez, E., \& Molinero Hernando, F. (2019). Criterios de la Unesco para la declaración de regiones vitícolas como paisaje cultural: su aplicación al caso español. Boletín de la Asociación de Geógrafos Españoles, 80, 2614, 1 33. https://doi.org/10.21138/bage.2614

Martínez Yáñez, C. (2008). Patrimonialización del territorio y territorialización del patrimonio. Cuadernos de Arte de la Universidad de Granada, 39, 251-266. Retrieved from https://revistaseug.ugr.es/index.php/caug/article/view/300

Mata Olmo, R. (2010). La dimensión patrimonial del paisaje: una mirada desde los espacios rurales. In Maderuelo (Coord.). Paisaje y patrimonio (pp. 31-74). Madrid: Abada.

Mata Olmo, R. (2017). El Plan Nacional de Paisaje Cultural. Una iniciativa para el conocimiento, la cooperación y la salvaguardia de paisajes de alto interés cultural. In A. Serrano Rodríguez (Coord.), Ordenación del territorio, urbanismo y medio ambiente en un mundo en cambio (pp. 287-302). Valencia: Universitat de València. 
Múgica de la Guerra, M., Montes, C., Mata Olmo, R., \& Castell Puig, C. (2020). Las áreas protegidas como herramientas para reforzar las conexiones entre ciencia, gestión y sociedad. Ecosistemas, 29(1), 1-8. https://doi.org/10.7818/ECOS.1904

Olso, D.M., Dinerstein, E., Wikramanayake, E.D., Burguess, N.D., Powell, G.V.N., Underwood, E.C., ... Kassem, K.R. (2001). Terrestrial ecoregions of the World: A new map of life on Earth: A new global map of terrestrial ecoregions provides an innovative tool for conserving biodiversity. BioScience, 51(11), 933-938.

https://doi.org/10.1641/0006-3568(2001)051[0933:TEOTWA]2.0.CO;2

Ortega Valcárcel, J. (1998). El patrimonio territorial: el territorio como recurso cultural y económico. Ciudades, 4, 31-48. https://doi.org/10.24197/ciudades.04.1998.31-48

Pardo Abad, C.J. (2011). El patrimonio industrial en España: Análisis turístico y significado territorial de algunos proyectos de recuperación. Boletín de la Asociación de Geógrafos Españoles, 53, 239-264. Retrieved from https://bage.agegeografia.es/ojs/index.php/bage/article/viewFile/1200/1123

Repetto, L. (2006). Memoria y patrimonio. Algunos alcances. Revista de Cultura Pensar Iberoamérica. Revista de Cultura, $8 . \quad$ Retrieved from https://www.oei.es/historico/pensariberoamerica/ric08a06.htm

Rodrigo Cámara, J.M., \& Díaz Iglesias, J.M. (2011). La representación cartográfica del paisaje cultural y el patrimonio inmaterial. PH: Boletín del Instituto Andaluz del Patrimonio Histórico, 19(77), 120-123. Retrieved from

http://www.iaph.es/revistaph/index.php/revistaph/article/view/3116/3116

Romero Calcerrada, R. (2002). Metodología para la planificación y desarrollo sostenible en espacios naturales protegidos europeos: Las zonas de especial protección para las aves. GeoFocus. Revista Internacional de Ciencia y Tecnología de la Información Geográfica, 2, 1-32. Retrieved from http://www.geofocus.org/index.php/geofocus/article/view/11

Ruiz Romero de la Cruz, M.M., Cruz Ruiz, E. de los R., \& Zamarreño Aramendia, G. (2017). Rutas enológicas y desarrollo local. Presente y futuro en la provincia de Málaga. International Journal of Scientific Management and Tourism, 3(1), 283-310. Retrieved from https://dialnet.unirioja.es/servlet/articulo?codigo $=5975075$

Sánchez Cortez, J.L. (2013). Los geoparques como entes de conservación vinculante: Geodiversidad, biodiversidad y patrimonio cultural. Nature and Conservation, 6(1), 46- 


\section{3. https://doi.org/10.6008/ESS2318-2881.2013.001.0003}

Silva Pérez, R., \& Fernández Salinas, V. (2017). El nuevo paradigma del patrimonio y su consideración con los paisajes: Conceptos, métodos y prospectivas. Documents d'Anàlisi Geogràfica, 63(1), 129-151. https://doi.org/10.5565/rev/dag.344

Silva Pérez, R., \& Fernández Salinas, V. (2018). Una vuelta de tuerca a las certificaciones territoriales. La figura de paisaje cultural de la Unesco como estrategia de marketing territorial. In Nuevas realidades Rurales en tiempos de crisis: territorios, actores, procesos y políticas (pp. 924936). Actas del XIX Coloquio de Geografía Rural de la Asociación de Geógrafos Españoles. II Coloquio Internacional de Geografía Rural. Granada, October 24-26.

Silva Pérez, R., \& Fernández Salinas, V. (2019). Los problemas patrimoniales de base territoriales de la Unesco y su proyección a escala planetaria. Una lectura crítica. In Crisis y espacios de oportunidad. Retos para la geografía (pp. 1275-1290). Actas del XXVI Congreso de la Asociación Española de Geografía. Valencia, October 22-25.

Silva Pérez, R., Fernández Salinas, V., \& Mała Olmo, R. (2018). Concepto, ámbito y significado de los paisajes patrimoniales. In F. Molinero, J. Tort, R. Mała, R. Silva, J.L. García, M.C. Porcal, \& E. Ruiz (Coords.), Paisajes patrimoniales de España (T. I, pp. 17-38). Madrid: Ministerio de Agricultura, Pesca y Alimentación/Ministerio para la Transición Ecológica/con la colaboración de la Universidad Autónoma de Madrid, 2 T.

Spalding, M.D., Fox, H., \& Allen, G. et al. (2007). Marine ecoregions of the World: A bioregionalization of coastal and shelf areas. BioScience, 57(7), 573583. hitps://doi.org/10.1641/B570707

Stehpens, J., \& Tiwari, R. (2015). Symbolic estates: Community identity and empowerment through heritage. International Journal of Heritage Studies, 21(1), 99114. https://doi.org/10.1080/13527258.2014.914964

Troitiño Vinuesa, M.A. (2012). Turismo, patrimonio y recuperación urbana en ciudades y conjuntos históricos. Patrimonio cultural de España, 6, 147-164. Retrieved from http://www.academia.edu/download/32921161/Turismo_patrimonio_y_recuperacion_ur $\underline{\text { bana.pdf }}$

Udvardy, M.D.F. (1975). A classifation of the Biogeographical Provinces of the World. Morgues (Switzerland): International Union for Conservation of Nature and Natural Resources. Retrieved from http://www.fnad.org/Documentos/A\%20Classification\%20of\%20the\%20Biogeographical 
Unesco (1972a). Convención para la protección del Patrimonio Mundial cultural y natural. Retrieved from https://whc.unesco.org/archive/convention-es.pdf

Unesco (1972b). The Statutory Framework of the World Network of Biosphere Reserves. Retrieved from

https://www.environment.gov.za/sites/default/files/docs/statutory_framework.pdf

Unesco (1996). Reservas de biosfera: La Estrategia de Sevilla y el Marco Estatutario de la Red Mundial. Unesco, Paris (Francia). Retrieved from http://rerb.oapn.es/images/PDF_publicaciones/oapn_mab_estrategia_sevilla_tcm744172.pdf

Unesco (2013). Formulario de propuesta de Reserva de Biosfera. Programa el Hombre y la $\begin{array}{lllll}\text { Biosfera } & \text { (MAB). Programa } & \text { MaB. Retrieved }\end{array}$ from http://www.unesco.org/new/fileadmin/MULTIMEDIA/HQ/SC/pdf/biosphere_reserve_ nomination_form_2013_es.pdf

Unesco (2014). Elaboración de propuestas de inscripción en la Lista del Patrimonio Mundial. París: Unesco / Iccrom / Icomos / UICN / Centro del Patrimonio Mundial de la Unesco. Retrieved from https://www.iucn.org/es/content/elaboracion-de-propuestas-de-inscripcion-enla-lista-del-patrimonio-mundial-segunda-edicion-2011

Unesco (2015). Estatutos del Programa Internacional de Ciencias de la Tierra y Geoparques. Unesco. Retrieved from https://unesdoc.unesco.org/ark:/48223/pf0000260675_spa.page=4 Unesco (2019). Directrices prácticas para la aplicación de la Convención del Patrimonio Mundial. Retrieved from https://whc.unesco.org/en/guidelines/

Vadrí Fortuny, M.T., \& Tort Donada, J. (2017). A propósito de los paisajes culturales y su determinación jurídica: Un apunte acerca del proceso de toma de decisiones sobre los instrumentos de gestión. In Naturaleza, territorio y ciudad en un mundo global (pp. 2319-2327). Actas del XXV Congreso de la Asociación de Geógrafos Españoles. Madrid, October 25-27. Retrieved from

http://www.age-geografia.es/downloads/Naturaleza_Territorio_y_Ciudad_AGE2017.pdf Unesco (2018-2019). MaB brochure. Retrieved from http://www.unesco.org/new/fileadmin/MULTIMEDIA/HQ/SC/images/Spanish_MAB_leaflet_ 2018.pdf 
Zárate Martín, M.A. (2017). Paisajes culturales urbanos, oportunidad para la conservación del patrimonio y el turismo sostenible. Estudios Geográficos, 77(281), 693728. https://doi.org/10.3989/estgeogr.201624 